\title{
RECENTES APLICAÇÕES DO ORGANOFOTOCATALISADOR 1,2,3,5-TETRAQUIS(CARBAZOL-9-IL)-4,6- DICIANOBENZENO EM TRANSFORMAÇÕES QUÍMICAS
}

\author{
Lucas V. B. L. Pugnala ${ }^{a}$, Emanuele F. Pissinatia, Karina S. Quaglio e Márcio W. Paixão, ${ }^{a}$,,(i) \\ Departamento de Química, Universidade Federal de São Carlos, 13565-905 São Carlos - SP, Brasil
}

Recebido em 09/07/2020; aceito em 25/09/2020; publicado na web em 18/11/2020

\begin{abstract}
RECENT APPLICATIONS OF THE ORGANIC PHOTOCATALYST 1,2,3,5-TETRAKIS(CARBAZOL-9-YL)4,6-DICIANOBENZENE IN CHEMICAL TRANSFORMATIONS. Ruthenium and iridium polypyridine complexes are among the most employed photocatalysts described in literature. The broad applicability is due to the redox potentials and long half-life times of the excited state which these molecules presented. The pursuit for metal-free alternatives has been intensified in the last few years, therefore, many organic fluorophores were successfully employed as photocatalysts. Among them, 1,2,3,5-tetrakis(carbazol-9-yl)4,6-dicianobenzene (4CzIPN) recently drawn attention of the community, and it's been widely employed by distinguished research groups. Recent studies have shown that this catalyst do not only present similar properties to transition metal complexes, but also, its synthesis can be accomplished more easily and less expensive when compared with the metallic photocatalysts above mentioned. Therefore, 4CzIPN constitutes a metal-free alternative to replace transition metal complexes in conventional photochemical protocols. Moreover, it's as a powerful ally in the development of new photochemical approaches. In this work, we aim to summarize recent applications of $4 \mathrm{CzIPN}$ as catalyst in the emerging field of redox photocatalysis.
\end{abstract}

Palavras-chave: 4CzIPN; photocatalysis; organic photocatalyst; metal-free.

\section{INTRODUÇÃO}

Nas últimas décadas, devido à grande preocupação com o meio ambiente, pesquisadores vêm buscando o desenvolvimento de metodologias de síntese mais sustentáveis e verdes. Nesse contexto surge a fotocatálise, uma alternativa que emprega luz visível como fonte renovável de energia, possibilitando a geração de intermediários radicalares de forma mais branda quando comparada a outros métodos, já que não necessita de quantidades estequiométricas de fortes agentes redutores e/ou oxidantes. ${ }^{1}$

\section{Processos fotofísicos e fotoquímicos}

Os processos fotocatalíticos no geral se iniciam pela absorção de energia de uma fonte luminosa por uma molécula, o fotocatalisador. Após essa interação entre luz e matéria, dois tipos de processos diferentes podem ocorrer: os fotofísicos e os fotoquímicos.

Nos processos fotoquímicos, a interação entre a luz e a matéria pode levar a mudanças químicas estruturais. ${ }^{2} \mathrm{Ou}$ seja, em um processo fotoquímico, a molécula, ao absorver luz de uma fonte luminosa, promove um elétron de seu orbital molecular ocupado de maior energia (HOMO, do inglês highest occupied molecular orbital) para um orbital vazio de menor energia (LUMO, do inglês lowest unoccupied molecular orbital), criando então um estado eletrônico fotoexcitado. ${ }^{3}$ As energias necessárias para esses processos se encontram na faixa do ultravioleta e/ou da luz visível (UV-Vis), nas quais são permitidas as transições eletrônicas. ${ }^{2}$

Já nos processos fotofísicos, a estrutura química da molécula permanece inalterada ao final do processo. ${ }^{2} \mathrm{Nas}$ moléculas orgânicas, o estado fundamental é comumente um estado singleto, $\mathrm{S}_{0} \cdot{ }^{2}$ Quando uma molécula é exposta a uma luz com o comprimento de onda adequado, há uma grande probabilidade de pelo menos um fóton ser absorvido e, consequentemente, promover um elétron para o primeiro estado eletronicamente excitado, $\mathrm{S}_{1}{ }^{2}$ Essa transição de $\mathrm{S}_{0}$ para $\mathrm{S}_{1}$

*e-mail: mwpaixao@ufscar.br ocorre em um período de tempo entre $10^{-16}$ e $10^{-14}$ segundos. Além do estado singleto, também é possível que o elétron seja promovido ao estado tripleto, $\mathrm{T}_{\mathrm{n}}{ }^{2}$

Após a excitação, o elétron em $\mathrm{S}_{1}$ pode voltar ao estado fundamental $\mathrm{S}_{0}$ por meio de decaimentos radioativos ou não radioativos, como mostrado na Figura 1. Moléculas que passam por decaimentos radioativos emitem fótons quando o elétron excitado passa de $S_{1}$ a $S_{0}$, sendo esse processo observável por meio do fenômeno da fluorescência. ${ }^{2,3}$ No que se trata dos processos não radioativos, o excesso de energia é convertido em liberação de calor, um processo nomeado conversão interna $(\mathrm{CI}){ }^{2}$ Quando há a passagem do estado excitado singleto $\left(\mathrm{S}_{1}\right)$ para o estado excitado tripleto $\left(\mathrm{T}_{1}\right)$, transição proibida por spin, o processo é denominado cruzamento intersistemas (CIS), um termo geral para a interconversão de diferentes estados de spin. ${ }^{2}$ No estado tripleto, o decaimento pode ocorrer por processo radioativo (fosforescência) ou através de um decaimento não radioativo (CIS), fenômeno de grande importância para as transformações fotoquímicas. ${ }^{4}$ O decaimento do estado tripleto ocorre de maneira mais lenta, da ordem de nanossegundos a milissegundos, o que possibilita a participação dessas moléculas em processos bimoleculares, caracterizando esses processos como fotoquímicos. ${ }^{5}$

\section{Fotocatálise}

Um bom fotocatalisador deve ser capaz de ser fotoexcitado para que seja possível a sua participação em processos fotoredox com outras espécies. O tempo de meia-vida desse estado na ausência de um substrato deve ser grande o suficiente para permitir que, durante a fotocatálise, o catalisador e o substrato reajam eficientemente, ou seja, quanto maior a vida útil do fotocatalisador, maior será a probabilidade de reação. ${ }^{6} \mathrm{O}$ rendimento e a vida útil do estado singleto excitado podem ser obtidos a partir de medições de fluorescência, enquanto os dados correspondentes para o estado tripleto podem ser obtidos a partir de medições de absorção transitória.

$\mathrm{O}$ fotocatalisador, ao absorver luz em um comprimento de onda específico, gera um estado eletronicamente excitado e pode, então, 


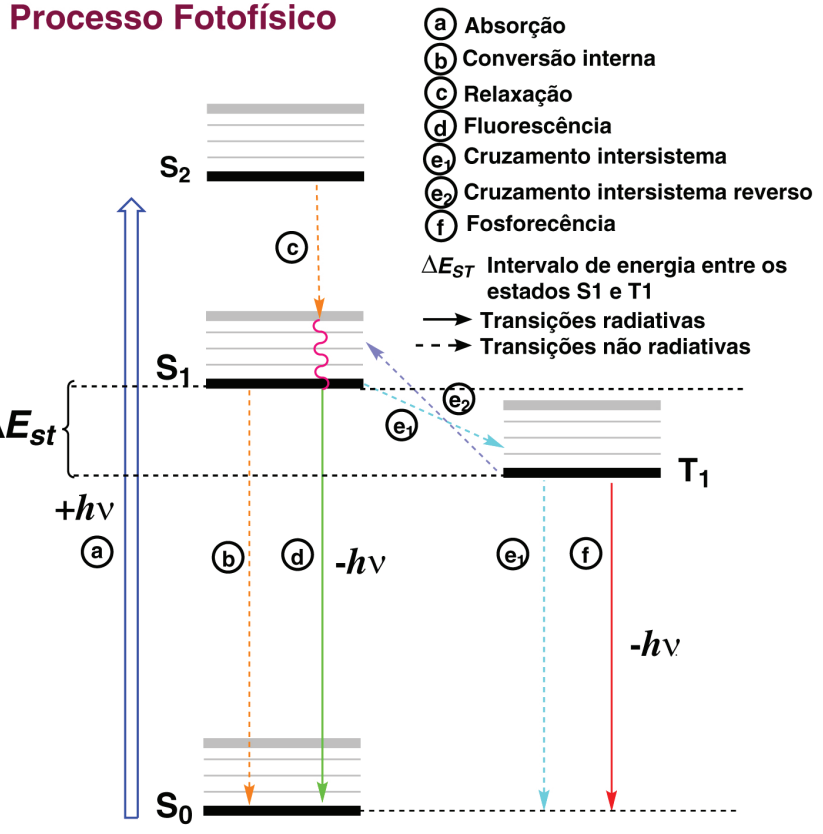

Figura 1. Diagrama de Jablonski simplificado

seguir dois caminhos distintos para realizar a troca de elétrons: o quenching oxidativo, representado na Figura $2 \mathrm{a}$, no qual ocorre a transferência de um elétron (TUE) do fotocatalisador excitado, denominado $[\mathrm{FC}]^{*}$, a uma molécula de substrato, gerando o fotocatalisador oxidado $[\mathrm{FC}]^{\cdot+}$; ou o quenching redutivo, representado na Figura 2b, no qual o fotocatalisador excitado abstrai um elétron do substrato, oxidando-o a partir de uma TUE, enquanto o fotocalisador se reduz, formando a espécie $[\mathrm{FC}]^{*}$. Posteriormente, $[\mathrm{FC}]^{\cdot+} \mathrm{e}$ $[\mathrm{FC}]^{*}$ podem ser regenerados por meio de uma reação de redução (Figura 2c) ou oxidação (Figura 2d), respectivamente, reagindo com uma molécula de sacrifício presente no meio reacional. Os produtos finais são o fotocatalisador e uma espécie iônica que reagirá com o substrato em seu estado fundamental. ${ }^{6}$

Ciclos catalíticos nos quais as etapas de oxidação e redução não necessitam do emprego de espécies de sacrifício são denominados ciclos redox-neutro. ${ }^{5}$

\section{Fotocatalisadores}

Fotocatalisadores são, então, espécies químicas capazes de absorver energia de uma fonte luminosa e de promover transferência de elétron entre as moléculas presentes no meio, gerando espécies que participarão de reações químicas subsequentes. Fotocatalisadores podem conter ou não metais de transição em sua estrutura.

Nesse sentido, metais de transição como rutênio e irídio, em especial seus complexos polipiridínicos, estão entre os catalisadores mais estudados e têm sido empregados com sucesso em diversas transformações químicas baseadas em fotocatálise redox (Figura $3 a){ }^{7}$ Como alternativas metal-free, muitos corantes orgânicos também são largamente estudados devido a sua capacidade de promover reações fotocatalisadas. Os mais conhecidos e estudados nessa classe são o Eosina Y, usado na remoção catalítica do grupo protetor éter $p$-metóxibenzil ${ }^{8}$ e na conversão de brometos benzílicos em benzaldeídos, ${ }^{9}$ e o Rosa Bengala, usado na $\alpha$-oxiaminação de aril cetonas ${ }^{10} \mathrm{e}$ em acoplamentos desidrogenativos, ${ }^{11}$ cujas estruturas estão representadas na Figura 3b.

Recentemente, moléculas da classe dos carbazoil dicianobenzenos, em especial o 1,2,3,5-tetraquis(carbazol-9-il)-4,6-dicianobenzeno (4CzIPN), têm atraído bastante atenção de pesquisadores em virtude da sua potencial aplicação como fotocatalisador orgânico livre de metais. Dentre outros aspectos, essa atenção se deve a seus potenciais de oxirredução e de seu elevado tempo de meia-vida no estado excitado, que são equiparáveis aos dos catalisadores baseados em metais de transição, como é o caso do $\left[\mathrm{Ru}(\mathrm{bpy})_{3}\right]\left(\mathrm{PF}_{6}\right)_{2}$ e dos catalisadores de irídio mostrados na Tabela 1. Ainda, tanto os potenciais de redução quanto os de oxidação do $4 \mathrm{CzIPN}$ são comparáveis com os do $\left[\operatorname{Ir}\left[\mathrm{dF}\left(\mathrm{CF}_{3}\right) \text { ppy }\right]_{2}-(\mathrm{dtbbpy})\right]\left(\mathrm{PF}_{6}\right)$. Os fotocatalisadores são fracos oxidantes/redutores de elétrons em seus estados fundamentais, porém, nos respectivos estados excitados, são potentes reagentes de transferência de elétrons. ${ }^{2}$ Uma comparação entre as características de diferentes fotocatalisadores está mostrada na Tabela 1.

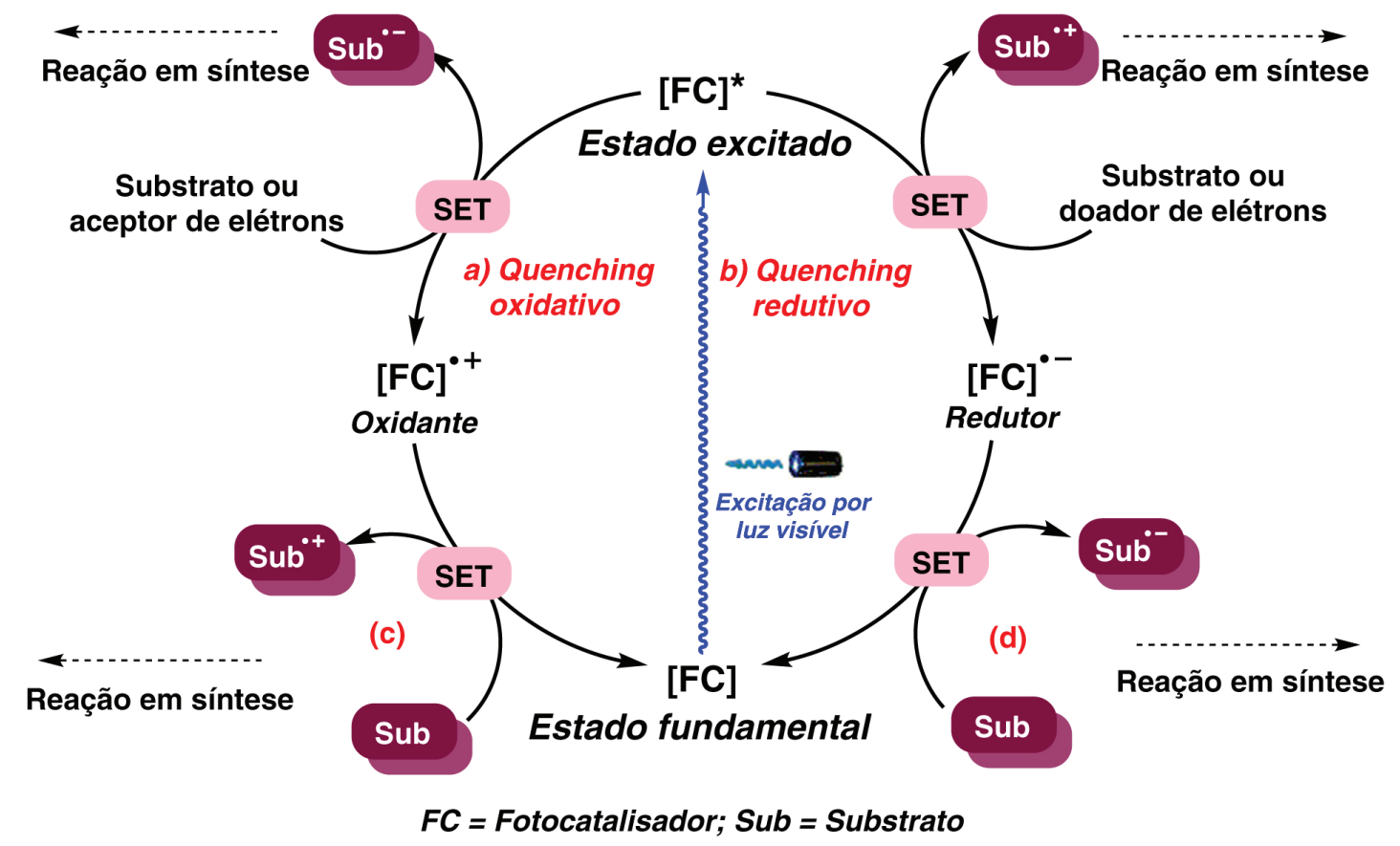

Figura 2. Ciclo catalítico 
a)

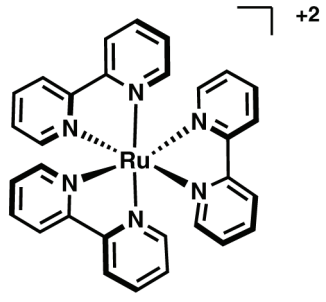

$\left[\mathrm{Ru}(\mathrm{bpy})_{3}\right]^{+2}$

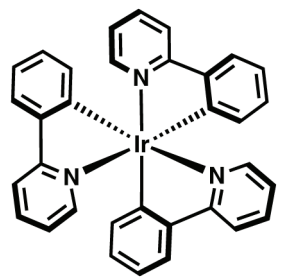

Fac-Ir(ppy) 3

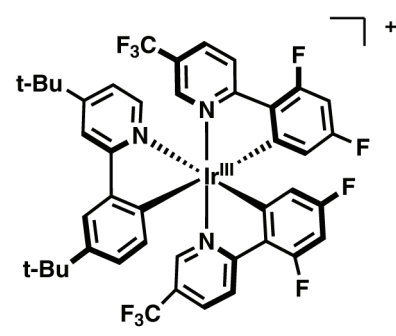

$\operatorname{Ir}\left[\mathrm{dF}\left(\mathrm{CF}_{3}\right) \text { ppy }\right]_{2}(\mathrm{dtbbpy})^{+}$

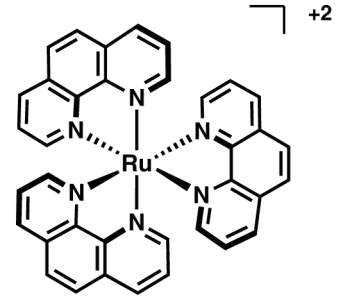

$\left[\mathrm{Ru}(\text { phen })_{3}\right]^{+2}$<smiles>NC(=O)c1c(Cl)c(Cl)c(Cl)c(Cl)c1-c1c2cc(I)c(=O)c(I)c-2oc2c(I)c(O[NH3+])c(I)cc12</smiles>

Rosa Bengala<smiles>O=C(O)c1ccccc1-c1c2cc(Br)c(=O)c(Br)c-2oc2c(Br)c(O)c(Br)cc12</smiles>

Eosina $Y$<smiles>Cc1cc(C)c(-c2c3ccccc3[n+](C)c3ccccc23)c(C)c1</smiles>

9-Mesitil-10-metilacridínio (Mes-Acr ${ }^{+}$)<smiles></smiles>

Riboflavina<smiles>O=C(O)c1ccccc1-c1c2ccc(=O)cc-2oc2cc(O)ccc12</smiles>

Fluoresceina

Figura 3. Estruturas dos catalisadores fotoredox. a) Complexos metálicos polipiridínicos de Rutênio e Irídio; b) Catalisadores orgânicos

Tabela 1. Comparação entre os potenciais redox e o tempo de meia vida dos estados excitados de diferentes fotocatalisadores

\begin{tabular}{|c|c|c|c|c|c|c|}
\hline \multirow[t]{2}{*}{ Fotocatalisador } & \multirow{2}{*}{$\lambda_{\text {abs máx }}(\mathrm{nm})$} & \multicolumn{2}{|c|}{$\begin{array}{l}\text { Potenciais redox do estado } \\
\text { excitado }(V)\end{array}$} & \multicolumn{2}{|c|}{$\begin{array}{l}\text { Potenciais redox do estado } \\
\text { fundamental }(\mathrm{V})\end{array}$} & \multirow{2}{*}{$\begin{array}{l}\text { Tempo de meia } \\
\text { vida no estado } \\
\text { excitado (ns) }\end{array}$} \\
\hline & & $\mathrm{E}_{1 / 2}\left(\mathrm{P}^{*+} / \mathrm{P}^{*}\right)$ & $\mathrm{E}_{1 / 2}\left(\mathrm{P}^{*} / \mathrm{P}^{*}\right)$ & $\mathrm{E}_{1 / 2}(\mathrm{P} * / \mathrm{P})$ & $\mathrm{E}_{1 / 2}\left(\mathrm{P} / \mathrm{P}^{-}\right)$ & \\
\hline $4 \mathrm{CzIPN}^{12}$ & 435 & -1.18 & +1.43 & +1.49 & -1.24 & 5.1 \\
\hline Eosina $\mathrm{Y}^{12}$ & 520 & -1.11 & +0.83 & +0.78 & -1.06 & 2.1 \\
\hline Rosa bengala ${ }^{13}$ & 549 & -0.99 & +0.84 & +0.81 & -0.96 & 0.5 \\
\hline Mes-Acr ${ }^{+12}$ & 424 & - & +2.08 & - & -0.57 & - \\
\hline Fluoresceina $^{12}$ & 491 & -1.55 & +1.25 & +0.87 & -1.17 & 4.2 \\
\hline$f a c-\operatorname{Ir}(\mathrm{ppy})_{3}{ }^{14}$ & 375 & -1.73 & +0.31 & +0.77 & -2.19 & 1.9 \\
\hline$\left[\operatorname{Ir}\left[\mathrm{dF}\left(\mathrm{CF}_{3}\right) \mathrm{ppy}\right]_{2}-(\mathrm{dtbbpy})\right]\left(\mathrm{PF}_{6}\right)^{14}$ & 380 & -0.89 & +1.21 & +1.69 & -1.37 & 2.3 \\
\hline$\left[\mathrm{Ru}(\mathrm{bpy})_{3}\right]\left(\mathrm{PF}_{6}\right)_{2}{ }^{14}$ & 452 & -0.81 & +0.77 & +1.29 & -1.33 & 1.1 \\
\hline$\left[\operatorname{Ru}(\text { phen })_{3}\right](\mathrm{Cl})_{2}{ }^{14}$ & 422 & -0.87 & +0.82 & +1.26 & -1.36 & - \\
\hline
\end{tabular}

\section{1,2,3,5-tetraquis(carbazol-9-il)-4,6-dicianobenzeno (4CzIPN)}

O 4CzIPN, cuja estrutura está representada na Figura 4a, e outras moléculas da classe dos carbazoil dicianobenzenos foram primeiramente reportadas como moléculas eletroluminescentes empregadas na fabricação de diodos orgânicos emissores de luz. ${ }^{15}$
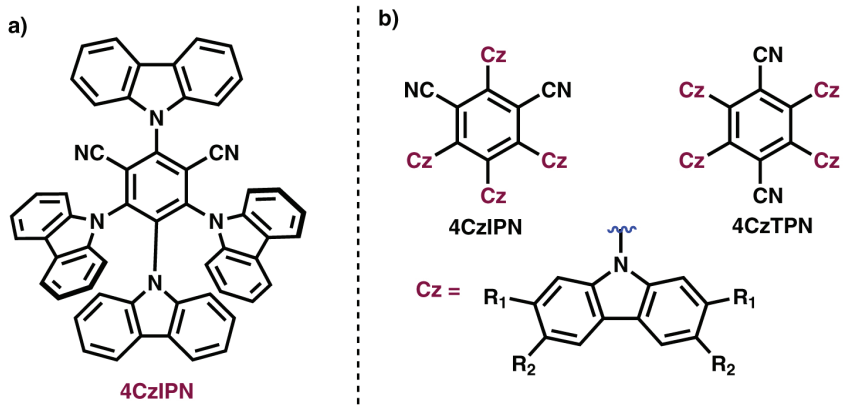

Figura 4. a) Estrutura 4CzIPN; b) Posições funcionalizáveis da porção carbazólica do 4 CzIPN
Tal aplicação é devido à baixa diferença de energia observada entre os estados excitados singleto e tripleto $\left(\Delta \mathrm{E}_{\mathrm{ST}}\right)$ desses compostos, o que possibilita a conversão do estado excitado tripleto $\left(\mathrm{T}_{1}\right)$ para o estado excitado singleto $\left(\mathrm{S}_{1}\right)$ num processo denominado cruzamento intersistemas reverso (CISR). Esse fenômeno permite que moléculas no estado $T_{1}$ apresentem fluorescência, mais especificamente fluorescência atrasada termicamente ativada (FATA), aumentando significativamente a eficiência dos diodos orgânicos emissores de luz produzidos a partir desses materiais.

A capacidade desses materiais de passarem por processos de CISR apresentando então FATA é fruto de um design molecular e está intrinsecamente ligado à sua estrutura molecular. Devido ao grande volume dos grupos carbazóis $(\mathrm{Cz})$, os mesmos se encontram distorcidos do plano ocupado pelo dicianobenzeno, apresentando um ângulo de aproximadamente $60^{\circ}$ entre as porções $\mathrm{Cz}$ e a porção dicianobenzênica. ${ }^{5}$ Dada essa distorção, seria esperado uma baixa interação eletrônica entre as porções doadoras e aceptoras de elétrons da molécula, representadas pelos grupos $\mathrm{Cz}$ e dicianobenzeno, respectivamente, levando à separação espacial dos orbitais de fronteira, o que de fato é confirmado por cálculos da Teoria do 
Funcional da Densidade. ${ }^{5}$ De acordo com os cálculos teóricos, o orbital preenchido de maior energia (HOMO) e o orbital vazio de menor energia (LUMO) estão localizados nas porções doadoras e aceptoras da molécula, respectivamente. A separação espacial destes e a restrição de suas interações eletrônicas, dado o ângulo diedral entre eles, têm como resultado o baixo $\Delta \mathrm{E}_{\mathrm{ST}}$ observado. ${ }^{5,16}$

Uma consequência direta da sobreposição orbitalar dos orbitais de fronteira é a possibilidade de se fazer modificações independentes nas porções doadoras e aceptoras da molécula, levando à obtenção de novas moléculas com propriedades fotofísicas e eletroquímicas distintas. No campo de aplicação dos diodos orgânicos emissores de luz, estudos relacionados à inserção de substituintes na porção $\mathrm{Cz}$ do $4 \mathrm{CzIPN}$ e outras moléculas da classe dos carbazoil dicianobenzenos exploraram esse conceito (Figura 4b). Quando os substituintes $R_{1}$ ou $R_{2}$ da porção carbazólica são trocados de $H$ para $\mathrm{CF}_{3}$, há o deslocamento hipsocrômico. ${ }^{16}$ Partindo do mesmo princípio, a alteração de $\mathrm{R}_{1}$ ou $\mathrm{R}_{2}$ por substituintes halogenados $(\mathrm{Cl}$, $\mathrm{Br}$ e I) em moléculas nas porções carbazólicas apresenta o efeito oposto, resultando num deslocamento batocrômico. ${ }^{17}$ No campo da fotocatálise, essa é uma ferramenta de extrema utilidade, uma vez que permite um ajuste fino das propriedades do catalisador de acordo com as características de cada sistema catalítico. ${ }^{18}$

Dessa forma, é possível afirmar que essa classe de catalisadores é versátil e possui grande potencial para ser aplicada em transformações químicas diversas.

Quanto a sua viabilidade, o 4CzIPN pode ser facilmente sintetizado em laboratório, por não necessitar de equipamentos mais modernos e complexos, além de ser comercialmente disponível. Sua síntese pode ser realizada em larga escala, como reportado pelo grupo de Christopher Kelly. ${ }^{19}$ Nela, adiciona-se a bis(trimetilsilil) amida de sódio (NaHMDS) a uma solução de 9H-carbazol em tetrahidrofurano (THF), desprotonando-o e formando o sal de $9 \mathrm{H}$-carbazol. A essa solução, adiciona-se tetrafluoro isoftalonitrila. O sistema é deixado em refluxo por $24 \mathrm{~h}$ a $65^{\circ} \mathrm{C}$ de forma a obter o 4CzIPN (Esquema 1).

O valor comercial do $4 \mathrm{CzIPN}$ é de $\$ 845 / \mathrm{g},{ }^{20}$ ao passo que o custo de síntese por essa metodologia é de aproximadamente $\$ 6 / g$, um baixo valor quando comparado com o valor de fotocatalisadores metálicos. $\mathrm{O}$ grupo de Molander realizou a síntese do $\left[\mathrm{Ru}(\mathrm{bpy})_{3}\right]\left(\mathrm{PF}_{6}\right)_{2}$ e do $\left[\operatorname{Ir}\left\{\mathrm{dF}\left(\mathrm{CF}_{3}\right)_{2} \mathrm{ppy}\right\}_{2}(\mathrm{bpy})\right] \mathrm{PF}_{6}$, cujos custos foram de aproximadamente $\$ 34 / \mathrm{g}$ e $\$ 160 / \mathrm{g}$, respectivamente. ${ }^{21}$ Ambos os catalisadores também são comerciais, sendo os valores de aproximadamente $\$ 134 / \mathrm{g}$ e $\$ 1400 / \mathrm{g}$, respectivamente.

Diante da sua grande aplicabilidade no ramo da fotocatálise, o $4 \mathrm{CzIPN}$ atingiu uma posição de destaque nos grupos de pesquisas, o que resultou em um artigo de revisão acerca dos seus recentes avanços em reações fotocatalíticas, publicado em 2019. ${ }^{22}$

\section{Técnicas de análises mecanísticas}

O conhecimento das propriedades físico-químicas dos substratos envolvidos em uma reação é de suma importância para o bom entendimento do mecanismo que a governa. Além disso, obter informações concisas sobre como tais substratos interagem entre si, quais intermediários se formam no meio reacional e quais são as potenciais reações que podem ou não ocorrer nesse meio é um ponto chave para que se possa propor o mecanismo de uma dada reação.

Embora ainda escasso, o emprego de técnicas analíticas para auxiliar no desenvolvimento e melhor entendimento de reações fotocatalisadas vem se popularizando nos últimos anos. ${ }^{23}$ Dessa forma, diversas técnicas podem ser utilizadas no estudo e desenvolvimento de metodologias fotoquímicas. Algumas delas serão brevemente discutidas a seguir.

Uma vez que reações fotoquímicas são intrinsecamente dependentes da radiação luminosa, é indispensável o conhecimento do perfil de absorção da espécie fotocatalítica empregada. ${ }^{3} \mathrm{~A}$ forma mais comum de se obter tal informação é através do emprego da espectroscopia de UV-Vis. Dessa forma, com base no perfil de absorção, é possível concluir qual comprimento de onda da luz que é melhor absorvido pelo fotocatalisador, informação crucial para se escolher a melhor fonte de excitação para cada sistema fotocatalítico.

No que se trata de reações envolvendo etapas de transferência de um elétron é também importante conhecer os potenciais redox das espécies catalíticas e dos substratos empregados. ${ }^{23} \mathrm{O}$ método mais comum para se obter esses dados é através do emprego de voltametrias cíclicas. Do ponto de vista prático, os potenciais redox das espécies aceptoras e doadoras de elétrons devem ser complementares para garantir o bom funcionamento do ciclo catalítico. ${ }^{23}$

Além de conhecer as propriedades das espécies envolvidas na reação, adquirir informações de como elas interagem entre si é crucial para entender o mecanismo reacional. Nesse contexto, a análise de quenching de luminescência pode fornecer informações interessantes sobre quais espécies do meio são capazes de interagir com o fotocatalisador no seu estado excitado. ${ }^{23} \mathrm{~A}$ análise consiste em medir o espectro de emissão do fotocatalisador excitado na presença de diferentes concentrações dos demais substratos que compõem a reação. ${ }^{3}$ Nos casos em que o aumento da concentração do substrato acarreta na diminuição da intensidade da emissão luminosa da espécie fotoexcitada pode-se concluir que o substrato em questão pode agir como quencher. Dessa forma, tal experimento pode ser utilizado para

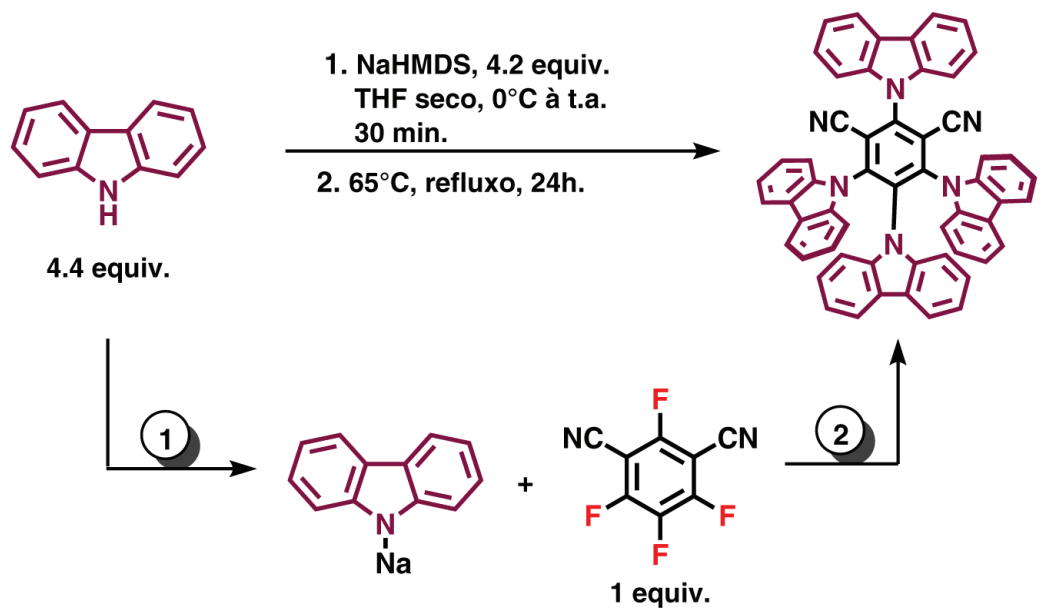

Esquema 1. Metodologia de síntese do $4 C z I P N$ 
determinar quais substratos do meio reacional interagem de fato com o fotocatalisador.

Por fim, a caracterização de intermediários reativos é uma forma valiosa de se determinar por quais caminhos a reação se procede. Entretanto, no que se trata de reações fotocatalisadas, a maioria dos intermediários consiste em espécies radicalares de curta duração, o que dificulta seu isolamento e caracterização. As três formas principais de averiguar a existência desses intermediários são através do uso de relógios radicalares,${ }^{24}$ da espectroscopia de ressonância paramagnética eletrônica (RPE) $)^{25}$ e da captura dessas espécies por uma armadilha para radicais, ${ }^{19}$ sendo essa última a forma mais direta. Essas armadilhas consistem em moléculas que reagem rapidamente com radicais formando espécies mais estáveis e de maior duração. Moléculas derivadas de nitróxidos alifáticos, como PNB e TEMPO, são as mais comumente utilizadas. ${ }^{23}$

\section{APLICAÇÃO DO 4CZIPN COMO FOTOCATALISADOR DE REAÇÕES ORGÂNICAS}

Com base em suas propriedades fotofísicas e fotoquímicas, equiparáveis aos fotocatalisadores baseados em metais de transição, é observado no 4CzIPN um grande potencial de aplicação em transformações fotoquímicas. Dessa forma, há exemplos de sua aplicação para a geração de espécies radicalares empregadas em uma série de transformações químicas de interesse na atualidade. Algumas dessas aplicações serão listadas nessa seção.

Compostos contendo porções ciclopropílicas em sua estrutura são amplamente encontradas em fármacos e metabólitos secundários. No geral, os métodos mais empregados para a obtenção desses compostos são relativamente complexos, como, por exemplo, a ciclopropanação de Simmons-Smith, ${ }^{26}$ além de raramente utilizarem condições moderadas e, por vezes, limitarem a diversidade de grupos funcionais dos compostos utilizados. Dessa forma, o desenvolvimento de metodologias de ciclopropanação a partir de precursores comerciais ou de fácil obtenção é de grande interesse tanto na academia quanto na indústria. Nesse contexto, Molander e colaboradores desenvolveram uma metodologia para a ciclopropanação de alcenos fotocatalisada por 4CzIPN sob irradiação de luz visível (Esquema 2). ${ }^{27}$

Foram realizados estudos controle e feita a otimização do experimento com o intuito de melhorar as condições e o rendimento reacionais. Nesses estudos, fotocatalisadores metálicos foram utilizados no lugar do 4CzIPN visando analisar suas atividades catalíticas na reação proposta. Diante dos menores rendimentos obtidos com o uso dos complexos de irídio e rutênio, foi possível demonstrar a eficiência do organofocatalisador. Os complexos Fac-Ir(ppy $)_{3}$ e $\left[\mathrm{Ru}(\mathrm{bpy})_{3}\right]\left(\mathrm{PF}_{6}\right)_{2}$ resultaram em apenas 74 e $71 \%$ de rendimento do produto desejado, respectivamente, enquanto o $\left[\mathrm{Ir}\left[\mathrm{dF}\left(\mathrm{CF}_{3}\right) \text { ppy }\right]_{2}-(\mathrm{dtbbpy})\right]\left(\mathrm{PF}_{6}\right)$ resultou em $92 \%$. Apesar desse alto valor obtido com o catalisador de irídio, ao se utilizar o 4CzIPN o rendimento obtido foi de $94 \%$, demonstrando não só a eficiência desse organofotocatalisador quando comparado com esses complexos, mas também sua alta atividade catalítica, além de ser uma ótima alternativa metal-free.

No trabalho em questão, o trietilamôniobis(catecolato) halometilsilicato sofre uma TUE de forma a gerar o radical halometílico, que é interceptado pela dupla ligação do alceno e forma o intermediário radicalar I. Esse radical é então reduzido pelo ânion radicalar do fotocatalisador num processo de TUE, regenerando o fotocatalisador no estado fundamental e formando a espécie aniônica II que promove uma ciclização 3-exo-tet, levando à formação do ciclopropano 3. O mecanismo proposto está descrito na Figura 5.

Também foram realizados alguns experimentos a fim de se obter maiores informações sobre o mecanismo da reação. Os primeiros experimentos analisaram a habilidade do alceno 1a (Figura 6) e do silicato 2c (Figura 7) de atuarem como quenchers de fluorescência do 4CzIPN.

Nesse estudo, uma amostra contendo apenas o fotocatalisador é fotoexcitada pela incidência de luz visível e a intensidade da fluorescência emitida pela amostra é medida em diferentes comprimentos de onda (neste caso, na faixa de 500 a $600 \mathrm{~nm}$ ). Posteriormente, mantendo a concentração do fotocatalisador, algumas amostras são preparadas contendo diferentes concentrações do substrato, com o objetivo de avaliar a habilidade de quenching. Mede-se, então, a intensidade de fluorescência do fotocatalisador na presença do substrato a ser estudado. Nesse caso, é possível afirmar que apenas o silicato atua como quencher do catalisador no seu estado excitado, uma vez que o aumento da concentração de silicato no meio diminui visivelmente a intensidade de fluorescência do fotocatalisador, ao passo que, independentemente da concentração de alceno no meio, o perfil de fluorescência do $4 \mathrm{CzIPN}$ pouco se alterou.

Utilizando a metodologia proposta, os autores sintetizaram 47 moléculas contendo o ciclopropano com uma grande diversidade estrutural e com rendimentos que variaram de $34 \%$ a $98 \%$. Alternativamente, empregando o trietilamôniobis(catecolato) clorometilsilicato, 7 compostos foram sintetizados, com rendimentos isolados de $14 \%$ a $92 \%$. Pouco estudo foi realizado empregando o silicato de bromo.

Com base nos bons resultados obtidos neste trabalho, o grupo de Molander desenvolveu ainda uma estratégia para a ciclopropanação de tosilatos homoalílicos empregando o 4CzIPN como fotocalisador sob irradiação de diodo emissor de luz azul (Esquema 3). ${ }^{28}$
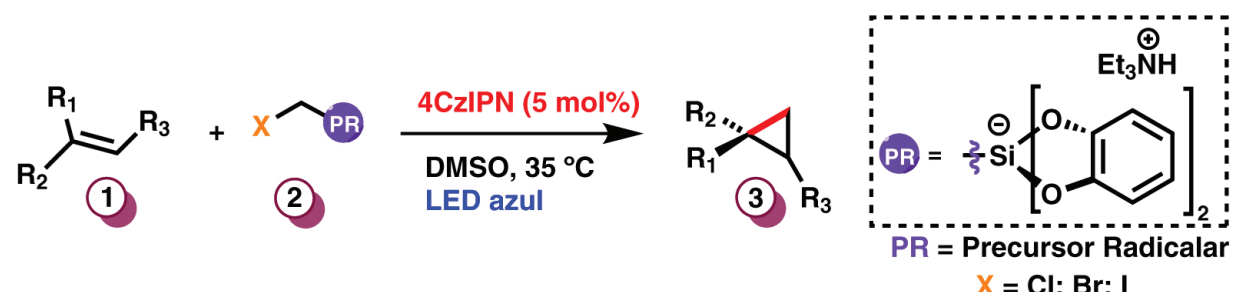

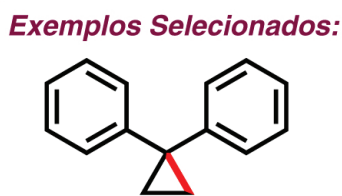

3a: $X=1 ; 98 \%$ 3b: $X=C l ; 92 \%$

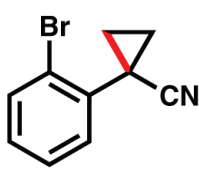

3c: $X=1 ; 95 \%$ 3d: $\mathrm{X}=\mathrm{Cl} ; 0 \%$

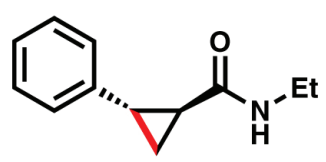

3e: $X=I ; 53 \%$ 3f: $X=C l ; 45 \%$

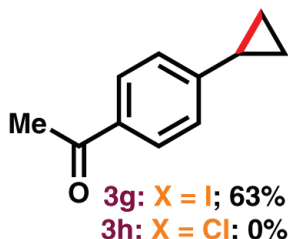

Esquema 2. Ciclopropanação de alcenos fotocatalisada por 4 CzIPN 


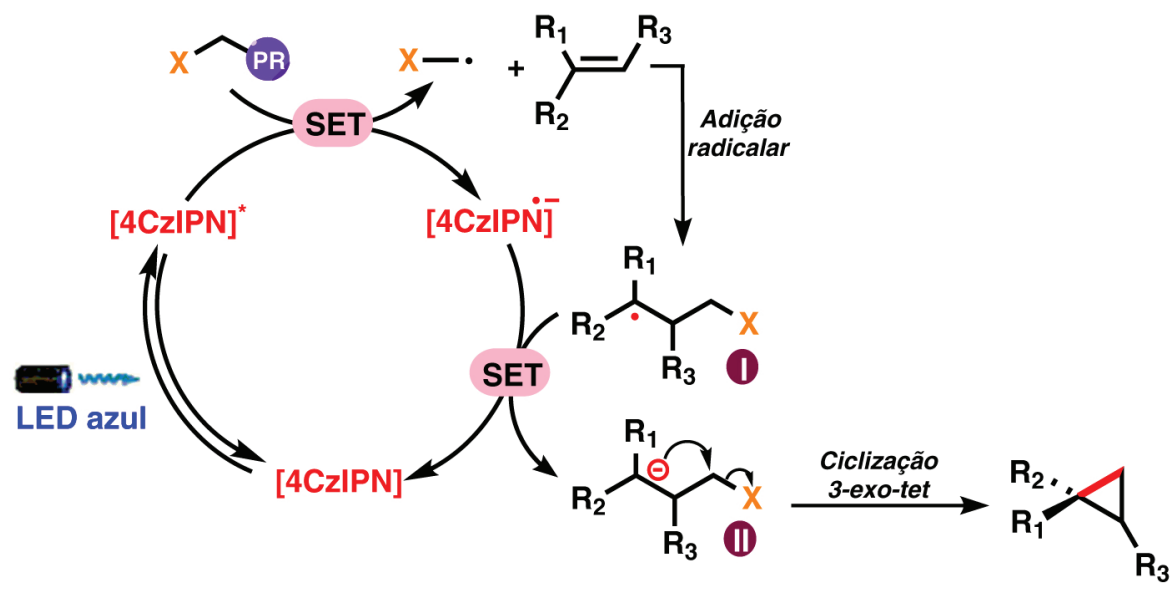

Figura 5. Proposta de mecanismo para ciclopropanação

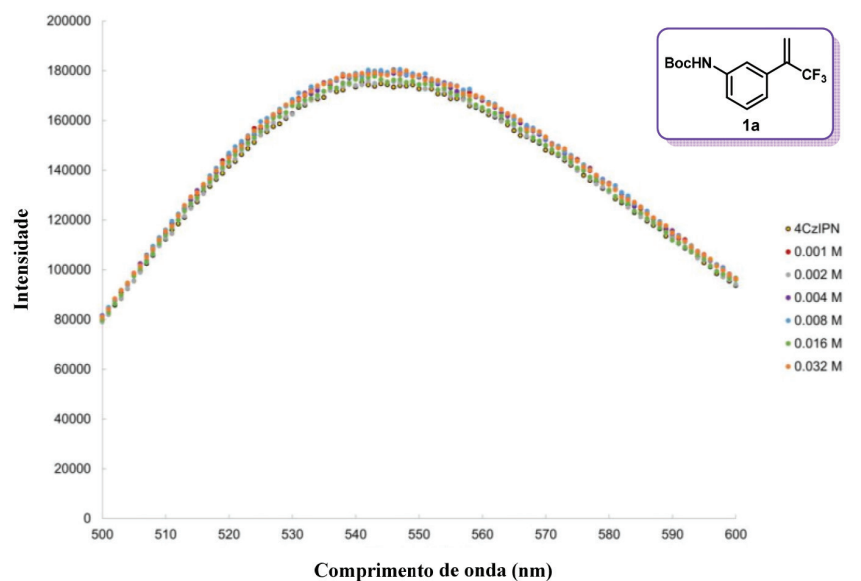

Figura 6. Capacidade de quenching por fluorescência de la versus comprimento de onda. Reimpresso com permissão do J. Am. Chem. Soc., 2018, 140, 8037. Copyright @ 2018 , American Chemical Society

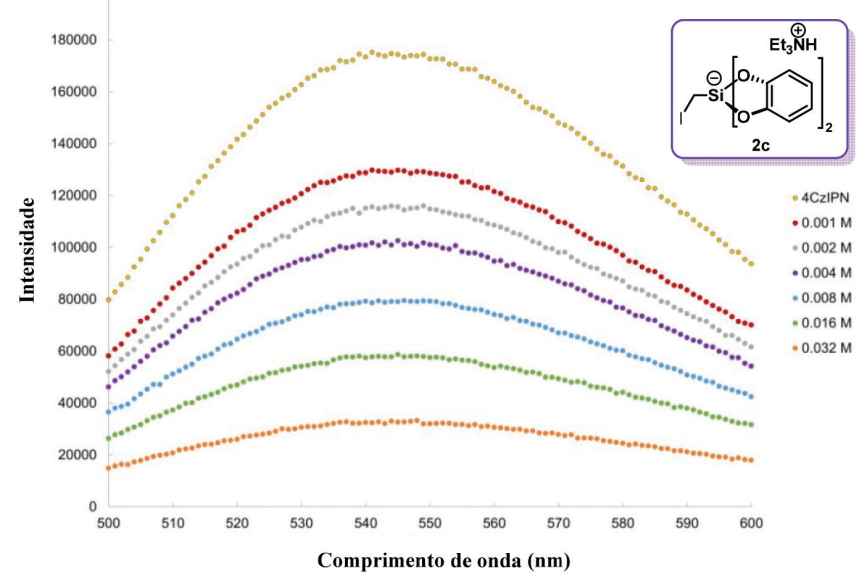

Figura 7. Capacidade de quenching por fluorescência de 2 c versus comprimento de onda. Reimpresso com permissão do J. Am. Chem. Soc., 2018, 140, 8037. Copyright $\odot 2018$, American Chemical Society

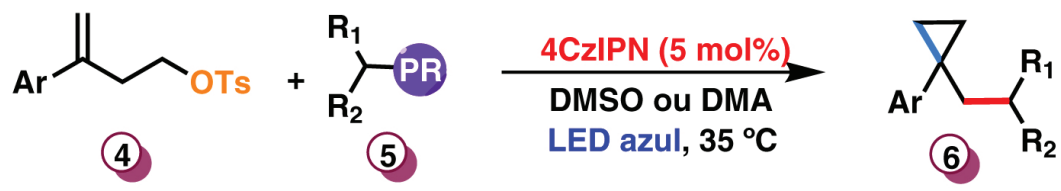

\section{Exemplos Selecionados:}
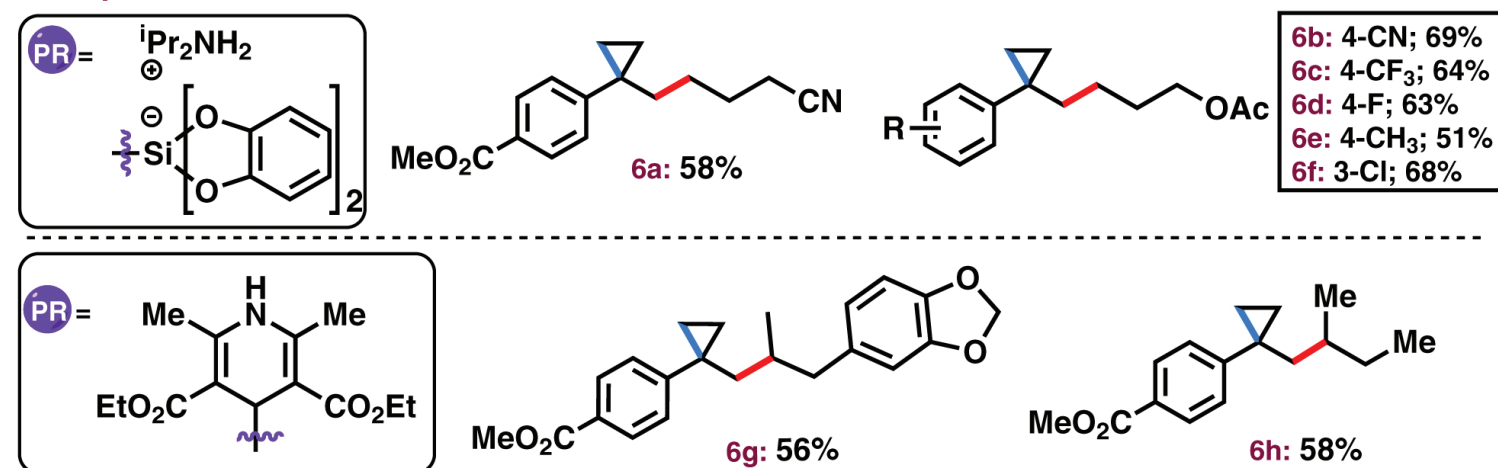

$\mathrm{PR}=\frac{3}{3} \mathrm{BF}_{3} \mathrm{~K}$<smiles>COC(=O)c1ccc(C2(CC3CCN(c4ccccn4)CC3)C3CCCC32)cc1</smiles><smiles>CC(=O)c1ccc(C2(CCOc3ccccc3)CC2)cc1</smiles>

$6 \mathrm{j}: \mathbf{8 1 \%}$ 
A condição padrão para essa reação foi estabelecida utilizando o 4CzIPN como organofotocatalisador e obtendo-se $87 \%$ de rendimento, determinado via cromatografia líquida de ultra performance (UPLC). Foram realizadas algumas modificações nessa condição padrão visando um aumento de rendimento. Dentre elas, o 4CzIPN foi substituído por catalisadores metálicos, tendo sido obtido rendimentos de $88 \%$ com o $\left[\mathrm{Ru}(\mathrm{bpy})_{3}\right]\left(\mathrm{PF}_{6}\right)_{2}$ e de $94 \%$ com o $\left[\mathrm{Ir}\left[\mathrm{dF}\left(\mathrm{CF}_{3}\right) \mathrm{ppy}\right]_{2}-(\mathrm{dtbbpy})\right]\left(\mathrm{PF}_{6}\right)$, mostrando-se bastante eficazes nessa reação. Apesar dos complexos metálicos resultarem em maiores valores, o 4CzIPN é uma alternativa metal-free que pode ser preparada a um custo significativamente menor e, portanto, foi o escolhido para esse trabalho.

De modo geral, essa abordagem representa uma metodologia que permite maior diversidade na síntese de ciclopropanos, uma vez que a porção eletrofílica da molécula na qual ocorrerá o ataque nucleofílico do ânion gerado pelo processo de transferência de um elétron se encontra nas olefinas empregadas, como mostrado na Figura 8. Dessa forma, qualquer radical capaz de reagir com a dupla ligação pode, a priori, ser empregado na reação de ciclização.

A fim de melhor entender como os efeitos eletrônicos nos tosilatos empregados interferiam no mecanismo reacional, um estudo de competição foi realizado. O estudo consistia em empregar diferentes análogos do tosilato 4 , contendo grupos $\sigma$ - ou $\pi$-retiradores de elétrons na posição para no anel aromático, na condição reacional otimizada.

Após análise de alíquotas dessas reações por UPLC, foi observado que os tosilatos mais deficientes de elétrons apresentaram melhores conversões para formação do produto de interesse nos primeiros minutos da reação, indicando que tosilatos deficientes de elétrons podem facilitar a adição de Giese nos momentos iniciais da reação e/ou estabilizam o intermediário aniônico IV.

Nesse trabalho, empregando as diferentes fontes de radical, tais como alquiltrifluorboratos de potássio e 4-alquildihidropiridinas, foram obtidos 30 ciclopropanos contendo diferentes grupos funcionais, como aminas e substituintes alquílicos, e com rendimentos de $43 \%$ a $97 \%$.

Ainda nesse contexto, Molander e colaboradores ${ }^{29}$ desenvolveram uma nova alternativa para obtenção de ciclopropanos policíclicos, de forma a usá-los como precursores de radicais bench-stable na catálise fotoredox (Esquemas 4 e 5).

Nos estudos de otimização, complexos metálicos foram utilizados, resultando em rendimentos de 10,5 e $16 \%$ a mais do que os obtidos com o 4CzIPN. Apesar de ser um valor considerável, os autores relataram que o $4 \mathrm{CzIPN}$ provou ser o fotocatalisador ideal para a reação, considerando especialmente a alta conversão do produto, o baixo custo do catalisador e sua natureza livre de metal, além de não ter sido necessário nenhum aditivo para conduzir a reação.

Nessa estratégia, o precursor de radical $\mathbf{V}$ oxida-se pela transferência de um elétron do fotocatalisador excitado, sofrendo, em seguida, uma fragmentação homolítica para formar o radical alquílico VI (Figura 9). Esse radical adiciona-se a VII, obtendo-se um radical $\alpha$-aril que será reduzido para produzir o ânion em VIII. O ânion então ataca a ligação eletrofílica adjacente ao grupo tosilato, fechando o anel e expulsando o grupo tosilato.

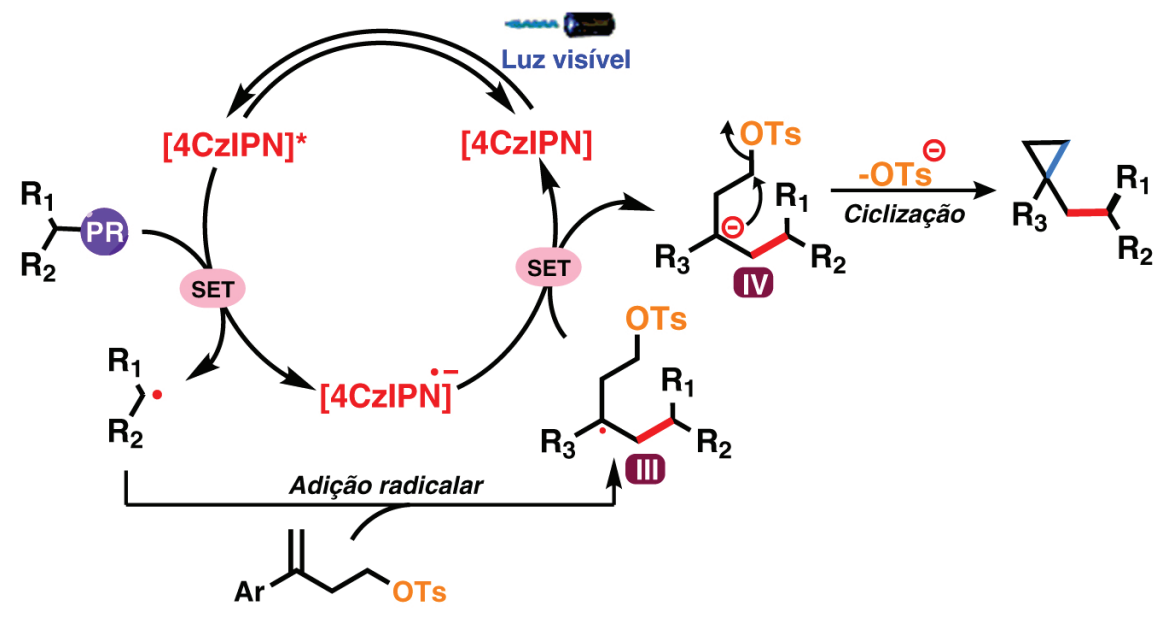

Figura 8. Proposta de mecanismo para ciclopropanação

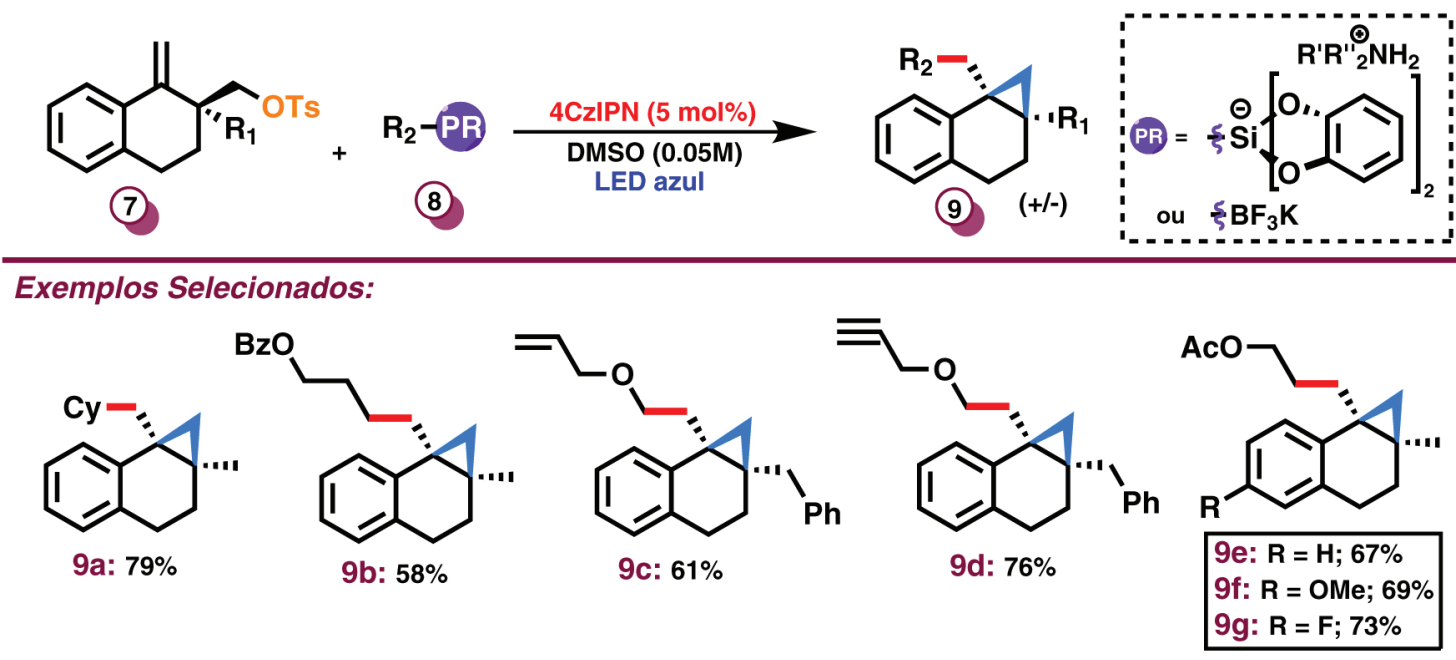

Esquema 4. Obtenção de ciclopropanos policíclicos 


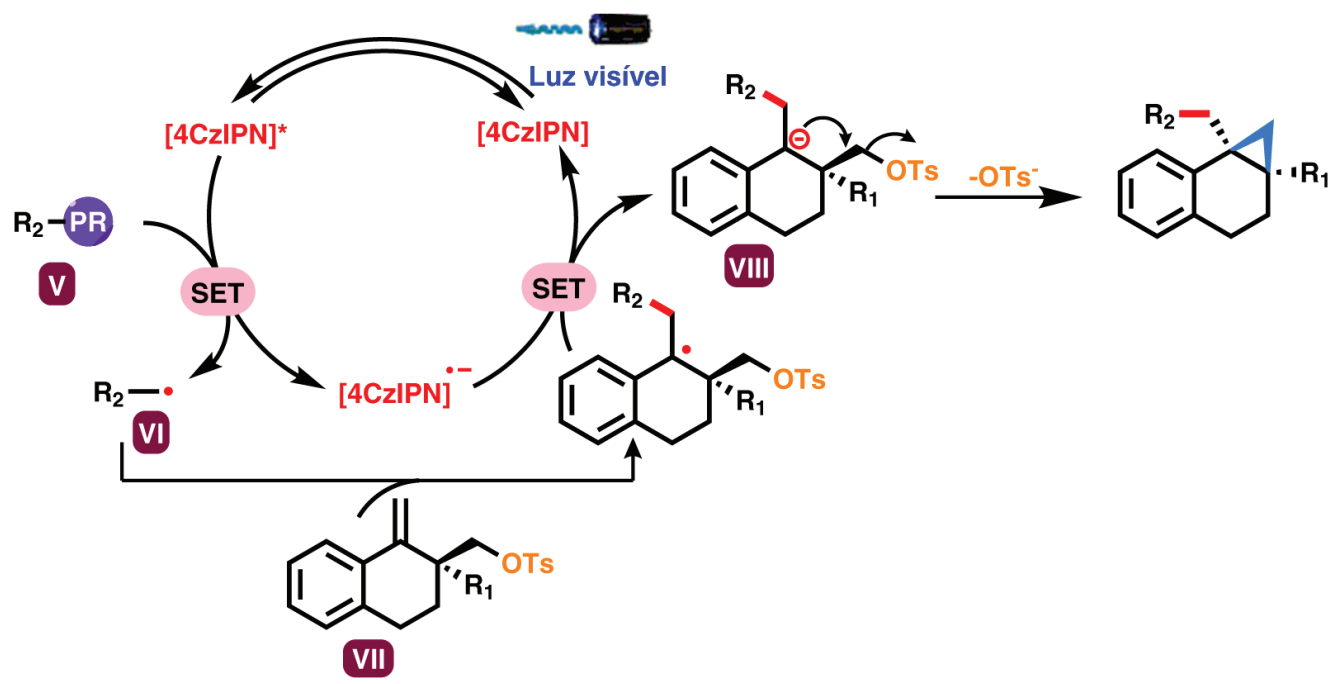

Figura 9. Proposta de mecanismo para a formação de ciclopropanos policíclicos

Com essa metodologia, a maior variedade de ciclopropanos policíclicos ( 24 exemplos) foi obtida a partir de tosilatos derivados da tetralona com rendimentos de 34 a $79 \%$.

Derivados da indanona também foram utilizados e 10 novos ciclopropanos com rendimentos que variaram de 52 a $82 \%$ foram obtidos (Esquema 5). Sistemas bicíclicos maiores também podem ser utilizados, tendo como precursor, por exemplo, derivados da benzocicloheptanona. Os rendimentos obtidos, no entanto, foram aquém do esperado, na faixa de 41 a $72 \%$, com caso no qual não houve formação do produto.

Reações que envolvem mecanismos em cascata empregando radicais também estão entre as mais empregadas para a síntese de moléculas complexas que apresentam grande aplicabilidade para indústrias em geral. Tendo isso em vista, a geração de radicais por meio de fotocatálise se apresenta como uma ótima forma de gerar radicais capazes de iniciar processos em cascata empregando condições brandas e sustentáveis.

Nesse contexto, Cai e colaboradores desenvolveram a trifluormetilação de álcoois alílicos empregando o 4CzIPN sob irradiação de diodo emissor de luz azul e utilizando $\mathrm{CF}_{3} \mathrm{SO}_{2} \mathrm{Na}$ como precursor de radicais (Esquema 6). ${ }^{30}$

A etapa de otimização das condições reacionais mostra claramente a superioridade do $4 \mathrm{CzIPN}$ em relação a fotocatalisadores baseados em complexos metálicos no sistema reacional proposto. O rendimento isolado do produto da reação modelo quando se empregou 4CzIPN (86\%) foi muito superior ao obtido para os complexos $\operatorname{Ir}(\mathrm{ppy})_{2}(\mathrm{dtbpy})$
$\mathrm{PF}_{6}(45 \%)$ e $\left[\mathrm{Ru}(\mathrm{bpy})_{3} \mathrm{Cl}_{2}\right]$ (traços), além de ter mostrado desempenho significantemente melhor que o complexo $\left[\operatorname{Ir}\left[\mathrm{dF}\left(\mathrm{CF}_{3}\right) \text { ppy }\right]_{2}(\mathrm{dtbbpy})\right]$ PF6 (68\%).

No sistema proposto, o catalisador no estado excitado abstrai um elétron do ânion sufinato levando à formação de $\mathrm{SO}_{2} \mathrm{e} \cdot \mathrm{CF}_{3}$, que reage com o álcool alílico formando um novo intermediário radicalar. A reação prossegue pela migração do grupo arílico gerando o intermediário radical IX que, após migração 1,2-arílica via radical spiro[2,5]octadienil X, dá origem à espécie radicalar XI. Por fim, o radical XI é oxidado e, após desprotonação, forma o produto $\beta$-trifluormetil- $\alpha$-aril cetona 14, como mostrado na Figura 10.

Nessa abordagem, dispensa-se a utilização de reagentes caros para a obtenção do $\mathrm{CF}_{3}$ radicalar, assim como o emprego de fortes oxidantes, como o persulfato de amônio, ${ }^{31}$ o que é comum em métodos convencionais para trifluormetilação de alcenos. Como resultado desse trabalho, foi realizada com sucesso a carbotrifluormetilação de 31 álcoois alílicos, sendo 10 simétricos (46-88\%) e 21 assimétricos (66-90\%). As condições reacionais se mostraram tolerantes para álcoois alílicos contendo tanto grupos substituintes retiradores quanto doadores de elétron presentes nos anéis aromáticos, independentemente de a posição ser orto, meta ou para.

Ainda no mesmo contexto e empregando o reagente de Langlois $\mathbf{1 3}$ como fonte de radicais $\mathrm{CF}_{3}$, o grupo de Cai aplicou uma metodologia semelhante para a síntese de oxindóis a partir da trifluormetilação de $\mathrm{N}$-acrilamidas (Esquema 7). ${ }^{32} \mathrm{~A}$ importância na síntese de oxindóis reside no papel significativo das amidas na

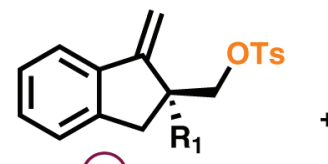

(10)

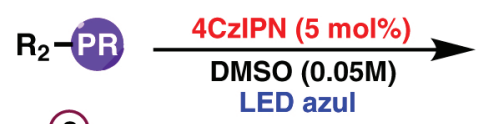

(8)

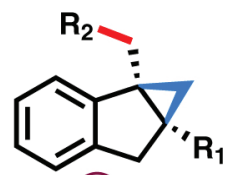

(11) $(+/-)$

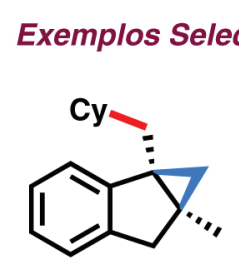

11a: $82 \%$

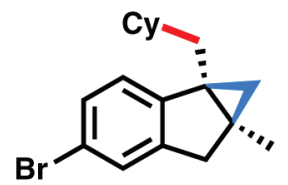

11b: $57 \%$

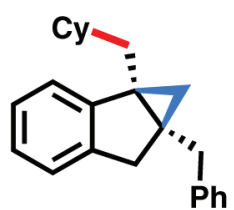

11c: $70 \%$
$\mathrm{AcO}$<smiles>CC(=O)OCCC[C@]12C[C@@]1(C)Cc1ccccc12</smiles>

11d: $58 \%$ 11e: $52 \%$

Esquema 5. Obtenção de ciclopropanos policíclicos com tosilatos derivados da indanona 


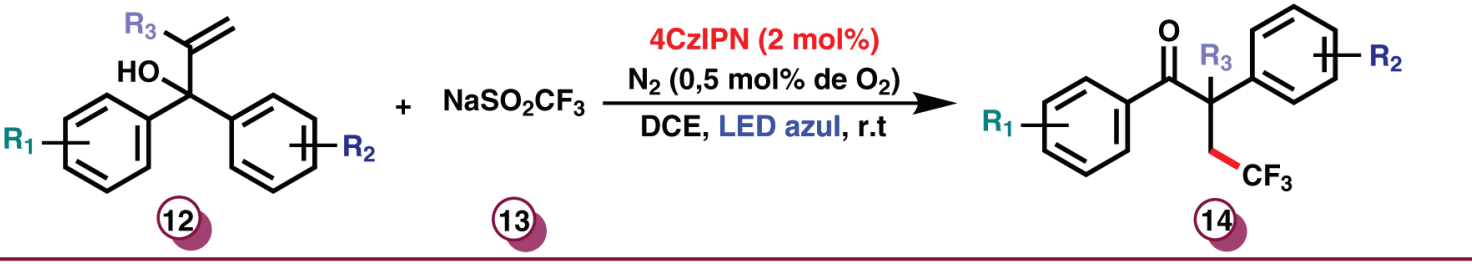

\section{Exemplos selecionados:}<smiles>O=C(c1ccc(Cl)cc1)C(CCC(F)(F)F)c1ccc(Cl)cc1</smiles>

14a: $83 \%$<smiles>CCC(C)(C(=O)c1ccc(Cl)cc1)c1ccc(Cl)cc1</smiles>

14b: $63 \% \mathrm{CF}_{3}$<smiles>COc1ccc(C(=O)C(CC(F)(F)F)c2ccccc2)cc1</smiles>

14c: $72 \%$<smiles>O=C(C1CCCCC1)C(CCC(F)(F)F)c1ccccc1</smiles>

14d: $74 \% \mathrm{CF}_{3}$

Esquema 6. Trifluormetilação de álcoois alílicos catalisada pelo 4 CzIPN

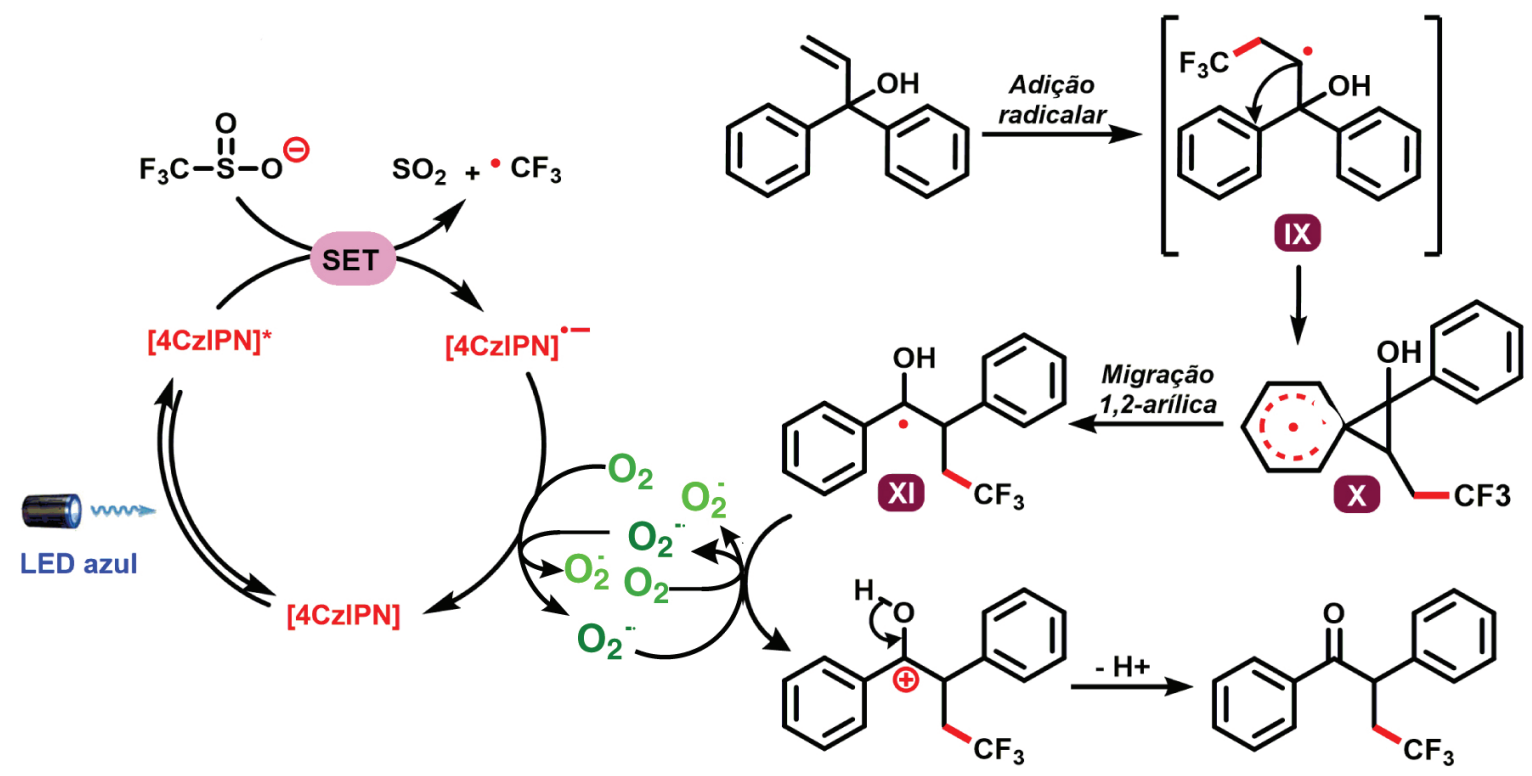

Figura 10. Proposta de mecanismo para a carbotrifluormetilação de álcoois alílicos

indústria farmacêutica, já que cerca de $70 \%$ dos fármacos cujos compostos ativos são pequenas moléculas orgânicas mais vendidos em 2018 possui uma ligação amida. ${ }^{33}$

Aqui, o emprego do 4CzIPN como fotocatalisador também se mostrou mais vantajoso em relação aos fotocatalisadores metálicos. Os estudos relacionados à otimização da condição reacional mostraram que o rendimento isolado do produto quando se utiliza o
4 CzIPN (83\%) é maior em relação aos complexos $\operatorname{Ir}(\mathrm{ppy})_{2}(\mathrm{dtbpy}) \mathrm{PF}_{6}$ (64\%), [ $\mathrm{Ir}\left[\mathrm{dF}\left(\mathrm{CF}_{3}\right) \mathrm{ppy}\right]_{2}$ (dtbbpy)]PF6 (71\%) e $\left[\mathrm{Ru}(\mathrm{bpy})_{3} \mathrm{Cl}_{2}\right]$ (traços). Inicialmente, o mecanismo dessa reação se processa de forma idêntica à descrita na Figura 10 , pela geração do radical $\bullet \mathrm{CF}_{3}$ a partir do composto 13. Esse radical se adiciona à $N$-acrilamida, o que resulta na formação do radical XII que, por ressonância, gera o intermediário XIII, sofrendo uma ciclização para dar origem ao radical XIV. Por<smiles>[R]N(C(=O)C(=C)[NH3+])c1ccc(Br)cc1</smiles>

(15)

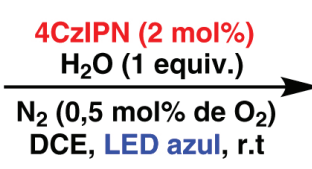

(13)<smiles>[R7]N1C(=O)[C@@]2(CC(F)(F)F)C1=Cc1[R7]c2cc1</smiles>

(16)<smiles>Cc1ccc2c(c1)[C@@](C)(COC(F)(F)F)C(=O)N2[N+](=O)[O-]</smiles>

16a: $83 \%$<smiles>CN([O-])C(=O)C1(C(C)(F)F)C(=O)N(C)c2ccc(Br)cc21</smiles>

16b: $91 \%$<smiles>CC1(CC(F)(F)F)C(=O)N(c2ccccc2)c2ccccc21</smiles>

$16 c: 89 \%$<smiles>CC(C)N1C(=O)[C@](C)(CC(F)(F)F)c2ccccc21</smiles>

16d: $82 \%$<smiles>CN1C(=O)[C@@](C)(CC(F)(F)F)c2cccnc21</smiles>

16e: $68 \%$

Esquema 7. Síntese de oxindóis a partir da trifluormetilação de $N$-acrilamidas catalisada pelo 4 CzIPN 
sua vez, XIV é oxidado e após desprotonação origina o oxindol 16, como descrito na Figura 11.

Os produtos foram obtidos com rendimentos de moderados a bons (41-91\%) e o sistema reacional se mostrou tolerante à $N$-acrilamidas contendo substituintes halogenados, retiradores e doadores de elétrons nas posições meta e para.

Além de seu alto potencial como fotocatalisador orgânico e das aplicações em diversas transformações como uma alternativa metalfree, há ainda exemplos na literatura em que o 4CzIPN é aplicado juntamente a um complexo de metal de transição em sistemas duplo catalíticos que exploram tanto os potenciais de oxirredução desse catalisador orgânico quanto as propriedades inerentes aos complexos metálicos aplicados. Dentre os complexos empregados nesses sistemas, os mais comumente utilizados são os complexos de níquel (Ni), embora o emprego de complexos de paládio também ocorra com certa frequência. Nesse contexto, o grupo de Melchiorre ${ }^{34}$ desenvolveu uma metodologia para conversão de brometos de heteroarila e arila em suas amidas correspondentes através de uma conversão catalítica combinando a catálise fotoredox e o uso de níquel à temperatura ambiente, processo nomeado catálise dupla fotoredox (dual catalysis photoredox) (Esquema 8).

Durante a etapa de otimização, os autores testaram os complexos $\operatorname{Ir}\left[\mathrm{dF}\left(\mathrm{CF}_{3}\right) \text { ppy }\right]_{2}(\mathrm{dtbpy}) \mathrm{PF}_{6}$ e $\operatorname{Ir}\left[\mathrm{dF}\left(\mathrm{CF}_{3}\right) \text { ppy }\right]_{2}(\mathrm{bpy}) \mathrm{PF}_{6}$ como fotocatalisadores e obtiveram rendimentos de $51 \%$ e $40 \%$, respectivamente. Por outro lado, a condição ótima, a qual emprega o $4 \mathrm{CzIPN}$ como fotocatalisador, levou à formação de produto com $99 \%$ de rendimento.

$\mathrm{O}$ mecanismo reacional se inicia com a formação do radical $\mathbf{X V}$ a partir da transferência de um elétron entre a dehidropiridina (DHP) e o organofotocatalisador 4CzIPN (Figura 12). Simultaneamente, o complexo de Ni(II) XVI, formado a partir da adição oxidativa entre o complexo de $\mathrm{Ni}(0)$ e o brometo de arila $\mathbf{1 8}$, captura o radical $\mathbf{X V}$ e

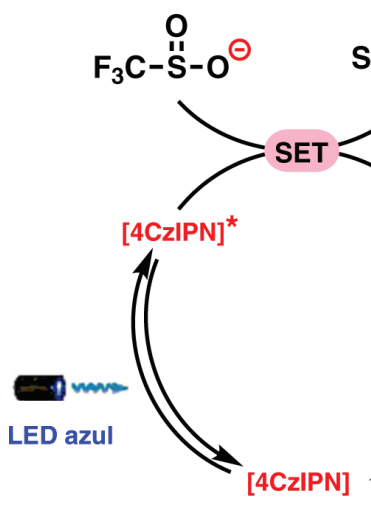

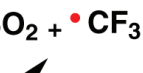<smiles>C=CC</smiles><smiles>CCCC</smiles>

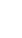<smiles>[R3]C(=C)C(=O)N([R2])c1ccc(Br)cc1</smiles><smiles>[R3]C(CC)C(=O)N([R2])c1ccc(Br)cc1</smiles>

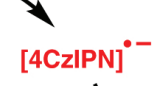<smiles>CC(C)CC(C)(C)C</smiles>

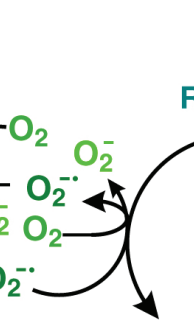<smiles>[R]N1C(=O)[C@]([R3])(CC(F)(F)F)c2ccccc21</smiles><smiles>[R3]C(CC)=C([O-])N([R2])c1ccc(Br)cc1</smiles>

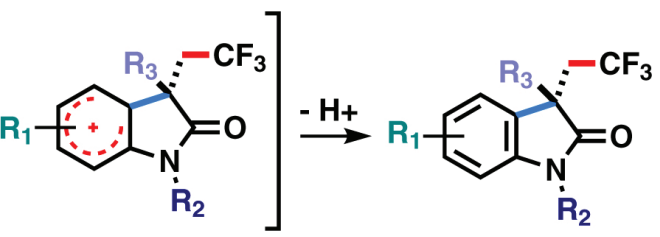

Figura 11. Proposta de mecanismo para a formação de oxindóis<smiles>[R]N([R])C(=O)C1C(C(=O)OCC)=C(C)NC(C)=C1C(=O)OCC</smiles>

(17)

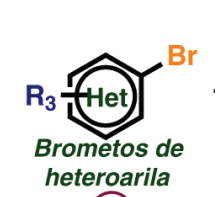

(18)

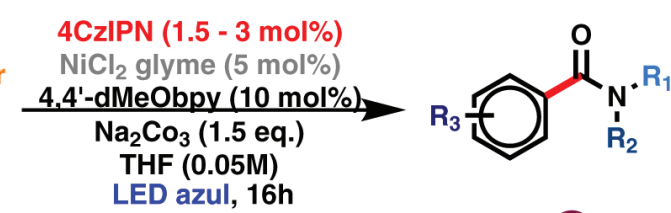

(19)

Exemplos Selecionados:<smiles>O=C(NC1CC1)c1ccc(C(F)(F)F)cc1</smiles>

19a: $99 \%$<smiles>O=C(c1ccc(C(F)(F)F)cc1)N1CCCCC1</smiles>

19b: $74 \%$<smiles>CC(=O)C(C)NC(=O)c1cnc2ccccc2c1</smiles>

19c: $86 \%$<smiles>COC(=O)[C@H](CC(C)C)NC(=O)C(Cc1ccccc1)NC(=O)c1ccc(C(F)(F)F)cc1</smiles><smiles>CC(=O)NC(=O)c1ccc(C(=O)O[C@H]2C[C@@H](C)CC[C@H]2C(C)C)cc1</smiles> 
forma o intermediário XVII. Após a eliminação redutiva, a ligação C-C do produto de acoplamento cruzado é formada, produzindo a amida 19.

Esse método proposto permite não só a preparação direta de amidas secundárias e terciárias, mas também a modificação de peptídeos, dada a prevalência de heterociclos contendo nitrogênio em moléculas biologicamente ativas no intuito de melhorar sua biodisponibilidade e estabilidade. Nesse estudo, foram obtidos 19 arenos com rendimentos de 36 a $99 \%$ e 10 heteroarenos com rendimentos de 35 a $86 \%$.

Ainda, o grupo de Cai estudou a geração de radicais $\alpha$-sulfinílicos a partir do dimetilsulfóxido (DMSO) e sua adição a álcoois alílicos, levando à formação de $\alpha$-aril- $\gamma$-metilsulfinil cetonas (Esquema 9). ${ }^{35}$

Os estudos de otimização mostraram que, nesse caso, o emprego de 4CzIPN implica em formação de produto com maior rendimento quando comparado ao uso de complexos metálicos em condições similares. O rendimento isolado do produto da reação que utiliza esse fotocatalisador orgânico foi de $89 \%$ contra $23 \%$ e $47 \%$ para os complexos $\left[\mathrm{Ru}(\mathrm{bpy})_{3} \mathrm{Cl}_{2}\right]$ e $\operatorname{Ir}\left[\mathrm{dF}\left(\mathrm{CF}_{3}\right) \mathrm{ppy}\right]_{2}(\mathrm{dtbpy}) \mathrm{PF}_{6}$, respectivamente.

$\mathrm{O}$ processo se inicia pela reação entre $\mathrm{PhI}\left(\mathrm{OCOCF}_{3}\right)_{2} \mathrm{e}$ 1,3,5-trimetoxibenzeno, levando à formação do intermediário XVIII que, posteriormente, reage com o fotocatalisador no estado excitado para a formação da espécie radicalar XIV (Figura 13). A reação prossegue pela abstração de um átomo de hidrogênio do DMSO e a consequente formação do radical $\alpha$-sulfinil XX. Esse radical se adiciona ao álcool alílico, formando o intermediário radicalar XXI que, após sofrer migração do grupo arílico, passa pelo intermediário XXII, originando a espécie XXIII. Essa espécie é oxidada e, após

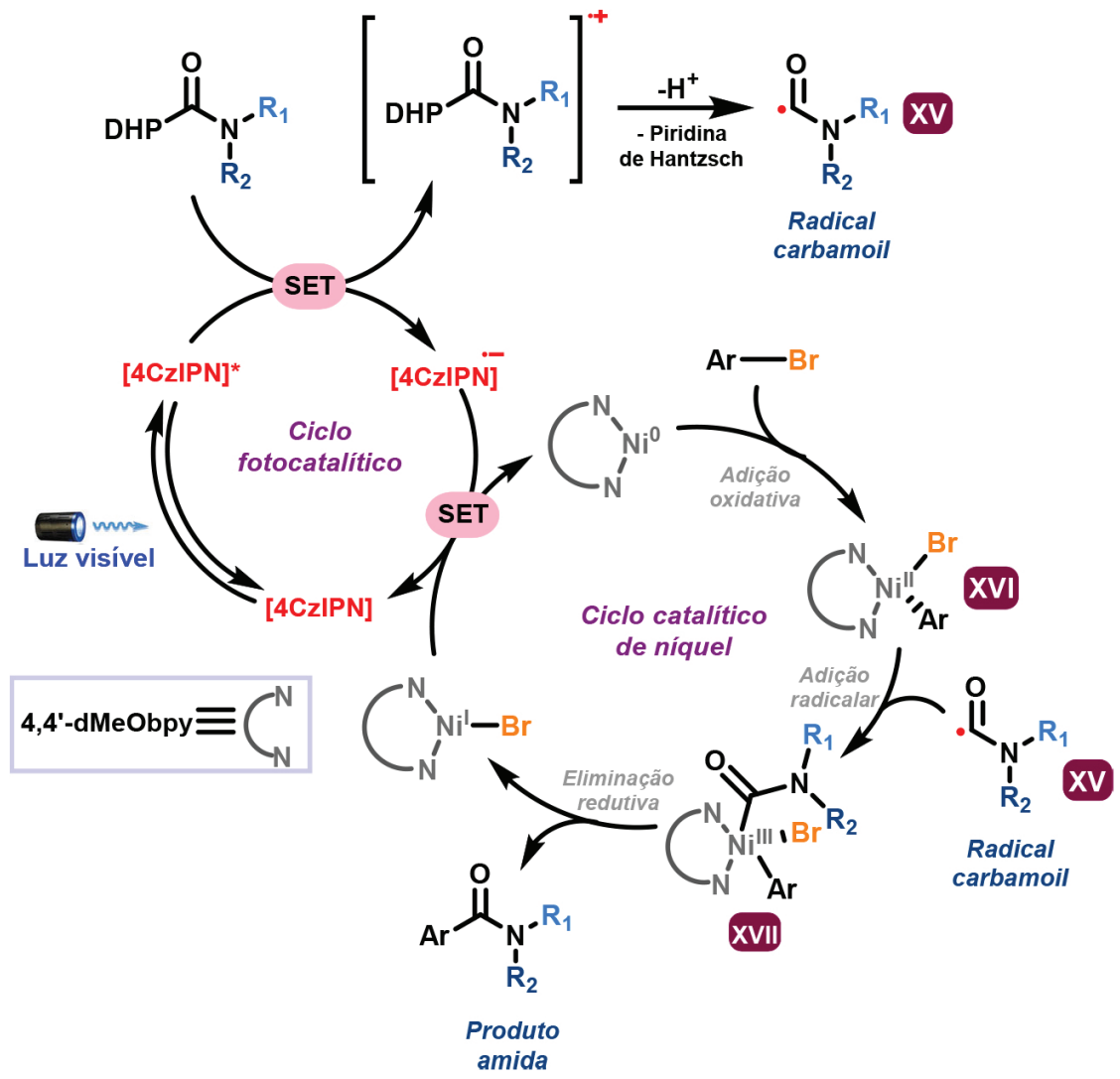

Figura 12. Proposta de mecanismo para formação de amidas a partir da fotocatálise dupla

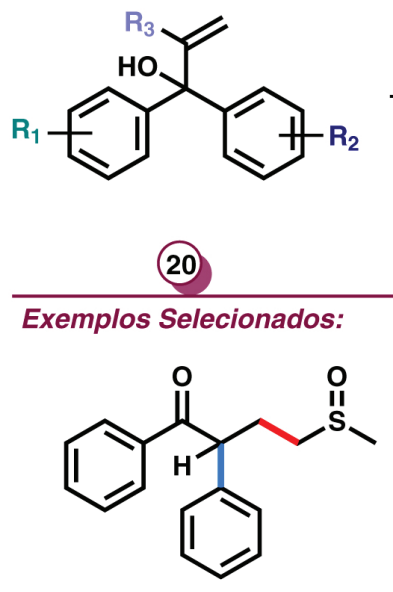

22a: $89 \%$<smiles>CS(C)=O</smiles>

(21)<smiles>CS(=O)CCC(C)(CCS(C)=O)c1ccccc1</smiles>

(22)

PIFA ( 2 equiv.)

1,3,5-trimetoxibenzeno (2 equiv.)

DCE, LED azul, r.t

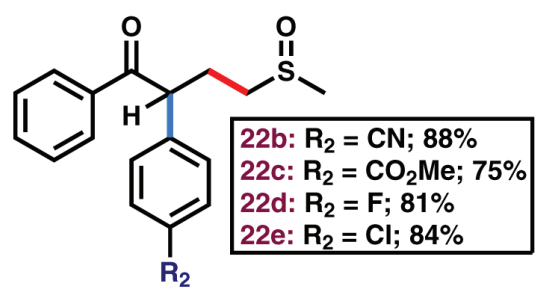<smiles>[R16]CCCC([R5])(CCS(C)=O)c1ccc(C(F)(F)F)cc1</smiles>

Esquema 9. Alquilação oxidativa de álcoois alílicos catalisada pelo 4 CzIPN 


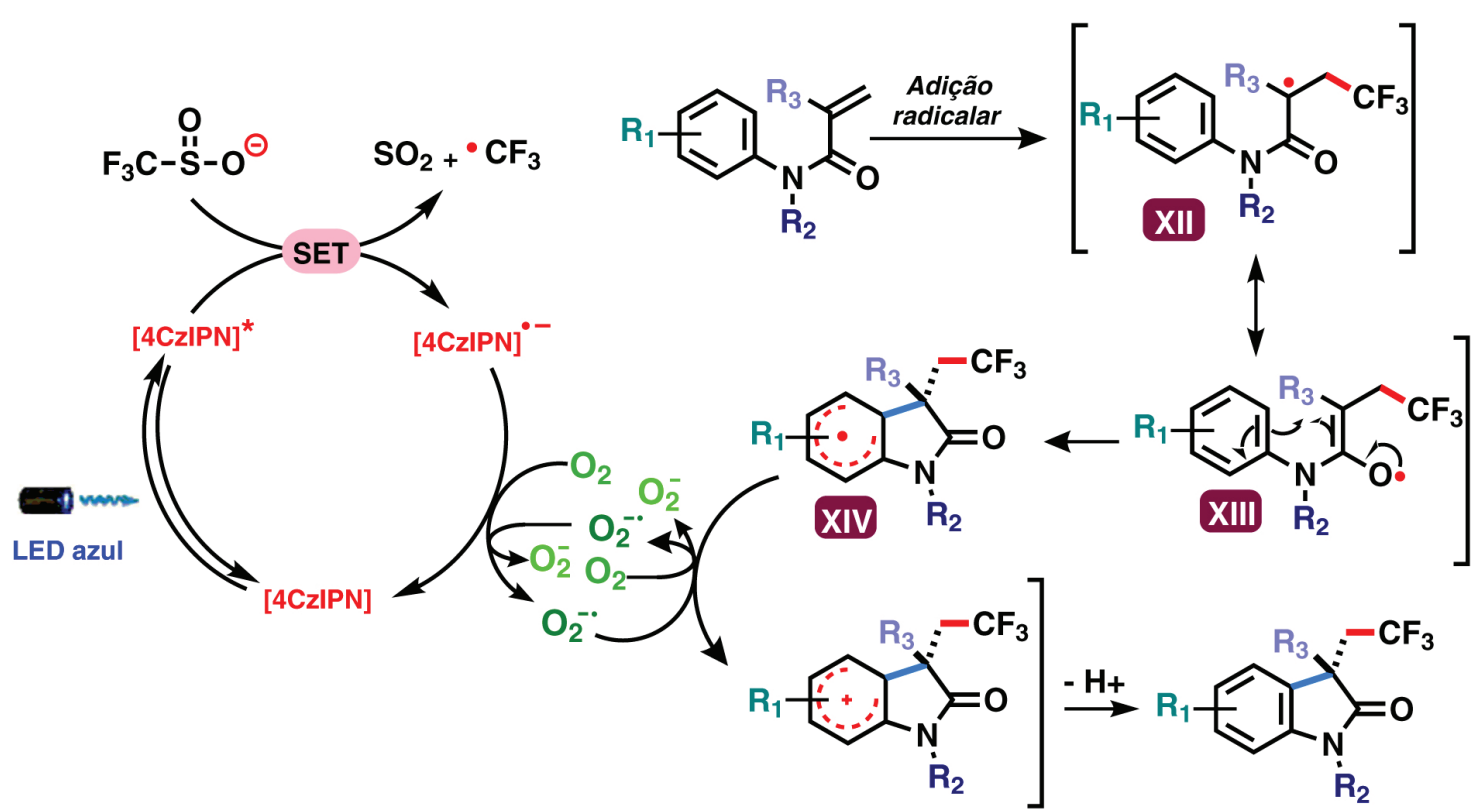

Figura 13. Proposta de mecanismo para a formação de $\alpha$-aril- $\gamma$-metilsulfinil cetonas

desprotonação, transforma-se no produto $\alpha$-aril- $\gamma$-metilsulfinil cetona 22.

Com o intuito de elucidar se o fotocatalisador excitado sofreu quenching pelo composto XVIII de iodo hipervalente (III), uma série de experimentos de quenching por fluorescência com o organocatalisador 4CzIPN foram realizadas (Figura 14).

De acordo com a Figura 14, o aumento na concentração do composto de iodo hipervalente (III) XVIII resultou em uma diminuição significativa da intensidade de fluorescência do 4CzIPN, o que sugeriu fortemente a participação do composto XVIII na TUE com o fotocatalisador.

A alquilação de diversos álcoois alílicos contendo anéis aromáticos substituídos nas posições meta e para se processou de forma eficaz tanto para substituintes doadores quanto retiradores de elétrons. Ao todo foram obtidos $34 \alpha$-aril- $\gamma$-metilsulfinil cetonas com rendimentos de bons a excelentes (49-92\%).

Nas reações citadas anteriormente, os radicais gerados pelo $4 \mathrm{CzIPN}$ foram interceptadas por ligações $\mathrm{C}=\mathrm{C}$. De forma análoga, moléculas contendo ligações $\mathrm{C}=\mathrm{N}$ também podem agir como aceptores de radicais, podendo, assim, serem empregadas em transformações fotoquímicas. Em contrapartida, também é possível a geração de radicais $\alpha$-amina a partir de processos de transferência de um elétron envolvendo ligações $\mathrm{C}=\mathrm{N}$, possibilitando reações de acoplamento radical-radical. Um exemplo desse tipo de reação foi

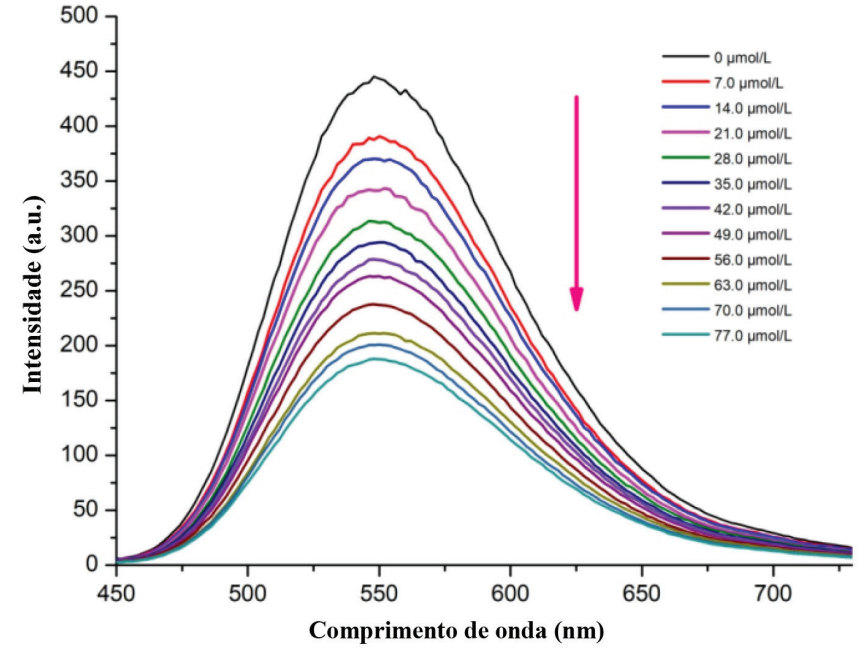

Figura 14. Espectro de fluorescência de 4CzIPN com diferentes concentrações do composto de iodo hipervalente (III) XVIII. Reimpresso com permissão do Org. Lett. 2018, 20, 23, 7611-7615. Copyright (C) 2018, American Chemical Society

reportado por Molander e colaboradores, no qual foram geradas ligações C-C a partir da reação entre biscatecolatos alquílicos e iminas catalisada pelo $4 \mathrm{CzIPN}$ em DMSO (Esquema 10). ${ }^{36}$

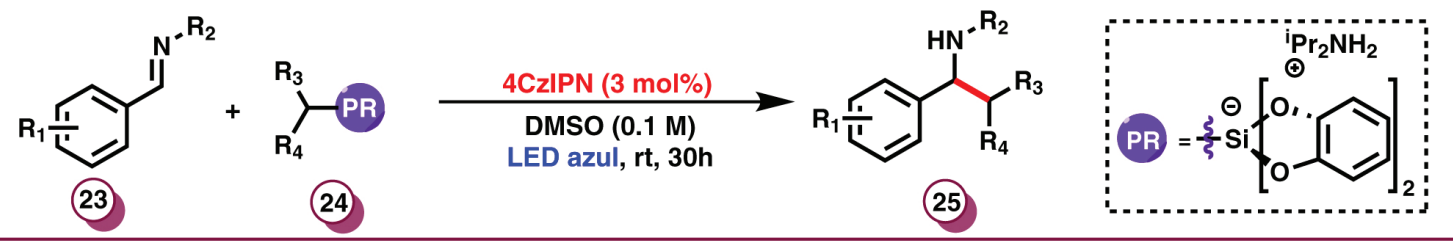<smiles>Cc1ccc(C(NS(=O)(=O)OCc2ccccc2)C2CCCCC2)cc1</smiles>

25a: $91 \%$<smiles>c1ccc(NC(c2ccccn2)C2CCCCC2)cc1</smiles>

25b: $78 \%$<smiles>CS(=O)(=O)NC(Cc1ccccc1)c1ccc(S(C)(=O)=O)cc1</smiles><smiles>COCCCC(Nc1ccccc1)c1ccc(Cl)cc1</smiles>

25d: $69 \%$ 
a)

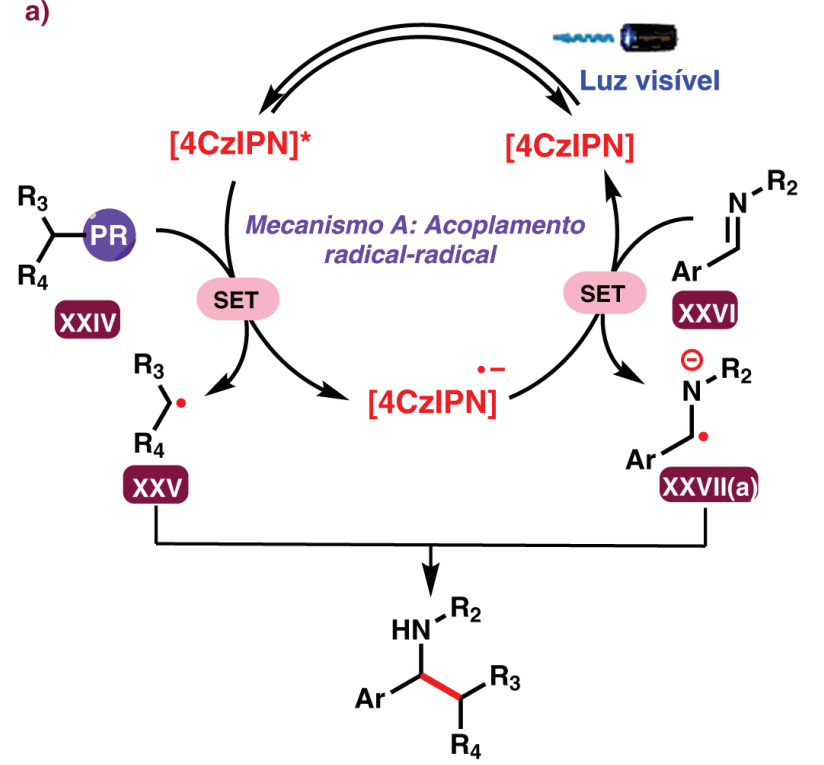

b)

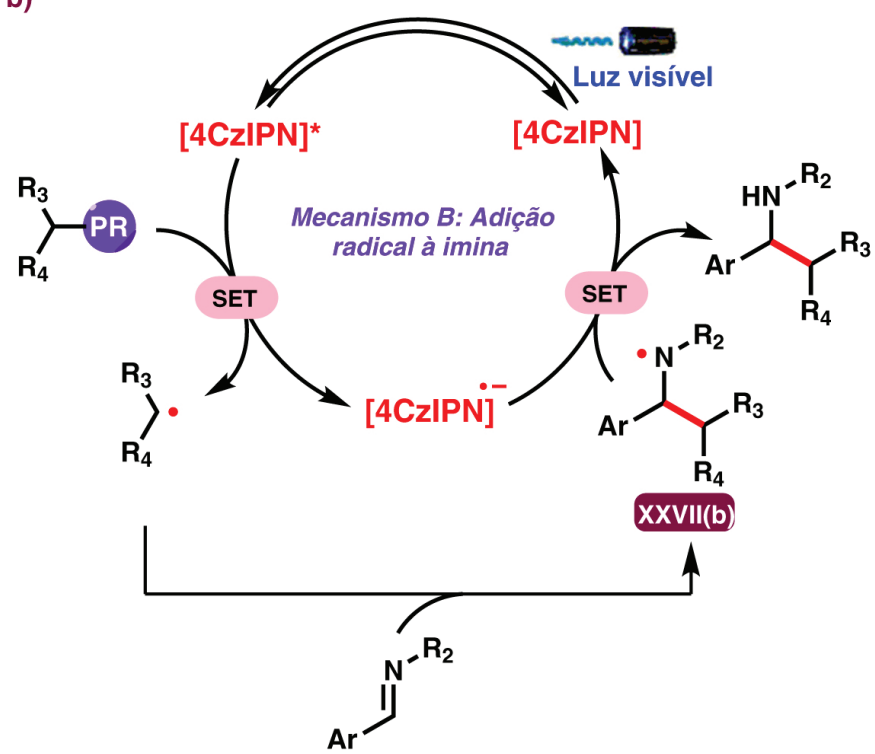

Figura 15. Propostas de mecanismos para a formação de aminas a partir de iminas

A escolha do DMSO como solvente foi feita com base em estudos que levaram em consideração o tempo de reação e o catalisador a ser utilizado. Feita essa otimização, os autores realizaram um estudo para definir qual o melhor catalisador a ser utilizado. Foram obtidas boas conversões ao se utilizar catalisadores de rutênio e irídio, sendo elas de $94 \%$ para o $\mathrm{Ru}(\mathrm{bpy})_{3}\left(\mathrm{PF}_{6}\right)_{2}$, de $97 \%$ para o $\left[\operatorname{Ir}\left\{\mathrm{dFCF}_{3} \text { ppy }\right\}_{2}(\mathrm{bpy})\right]$

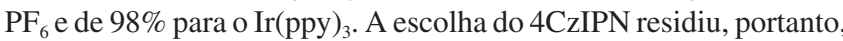
não só em sua maior eficiência, com conversão maior que $99 \%$, mas também no seu menor custo e por ser uma alternativa mais sustentável quando comparado ao catalisadores metálicos.

Para essa transformação, dois mecanismos reacionais foram propostos: a) a imina é reduzida por um processo de transferência de um elétron com o catalisador no seu estado reduzido, originando o ânion radical XXVII(a), cuja carga negativa está centrada no átomo de nitrogênio, que, por sua vez, realiza um acoplamento radicalradical com XXV, anteriormente gerado a partir do biscatecolato pela transferência de um elétron para o estado excitado do fotocatalisador, dando origem ao produto 25 (Figura 15a).

Alternativamente em b), o radical XXV se adiciona à imina XXVI, dando origem ao radical XXVII(b) centrado no átomo de nitrogênio. Subsequentemente, o catalisador reduzido doa um elétron ao radical XXVII(b), levando à formação do produto 25 (Figura 15b).

Para investigar o mecanismo reacional, foram realizados experimentos de voltametria cíclica e os dados eletroquímicos obtidos para quatro classes de iminas foram comparados com o potencial redox do 4CzIPN, como mostrado na Figura 16.
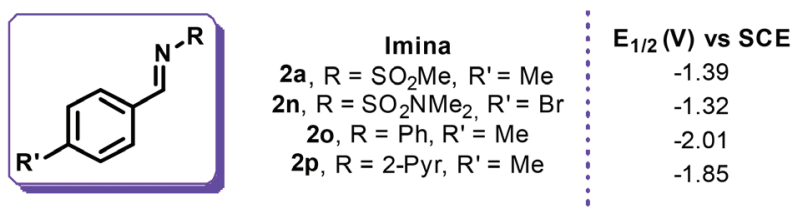

SCE= Eletrodo saturato de calomelano (Saturated Calomel Electrode)

Figura 16. $E_{1 / 2}$ de iminas medido a partir de voltametria cíclica

Com base nesses dados, o mecanismo descrito na Figura 15b é o mais provável para as $N$-ariliminas, devido à redução desfavorável da imina XXVI para formação do intermediário XXVII(a). Embora esse mecanismo também seja aplicável para iminas de $N$-sulfonil, o mecanismo descrito na Figura 15a não poderia ser descartado, dada a pequena diferença entre o estado fundamental reduzido do 4CzIPN $(-1.24 \mathrm{~V})$ e das iminas estudadas (Figura 16).

O sistema foi capaz de promover a alquilação tanto de $N$-aril quanto de $N$-sulfonil iminas contendo grupos doadores e retiradores de elétrons nas posições orto, meta ou para, levando à formação dos produtos com rendimentos entre $43 \%$ e $91 \%$.

Ainda no contexto de reagentes fluorados, Wang e colaboradores desenvolveram um método para o acoplamento multicomponente entre aldeídos, hidrazinas e reagentes bromodifluorados catalisado pelo 4CzIPN sob irradiação de luz visível (Esquema 11). ${ }^{37}$ Moléculas contendo porções difluormetilênicas apresentam grande aplicabilidade nas indústrias farmacêuticas e agroquímicas. ${ }^{38}$ Ademais, hidrazonas derivadas de aldeídos são importantes intermediários sintéticos, apresentando aplicações variadas.

No sistema reportado, a hidrazona derivada do aldeído gerada in situ participa de um processo de TEU com o catalisador no seu estado excitado formando o intermediário radical XXVIII ou XXIV (Figura 17). O fotocatalisador reduzido é então capaz de participar novamente de um processo de SET com a espécie de bromodifluorado 28, dando origem ao radical $\mathrm{CF}_{2} \mathrm{R} \mathbf{X X X}$. Esse radical $\mathbf{X X X}$ se adiciona ao intermediário XXIV, originando o aminocátion XXXI que, ao passar por um processo de tautomerização, leva à formação do produto desejado 29.

Com o intuito de confirmar o mecanismo radicalar sugerido, foram realizados experimentos de quenching por fluorescência. Os resultados obtidos indicaram que a reação ocorre via quenching redutivo do estado excitado do catalisador $4 \mathrm{CzIPN}$ pelos compostos 27 e XXVIII/XXIV, o que ainda foi corroborado pelas análises de voltametria cíclica dos substratos, uma forte sugestão de que o mecanismo proposto está correto.

A estratégia neste artigo dispensa o uso de reagentes caros e tóxicos normalmente empregados na síntese convencional de moléculas contendo difluoralcenos, além de evitar a utilização de metais caros como irídio e ouro, comumente empregados em transformações fotocatalíticas para a obtenção dessa classe de moléculas. Devido aos bons resultados obtidos com o $4 \mathrm{CzIPN}$ desde o início do estudo, não foram testados outros catalisadores. Ainda, foi possível a reciclagem desse organocatalisador, obtendo $95 \%$ de rendimento, sendo essa mais uma vantagem na sua escolha. 


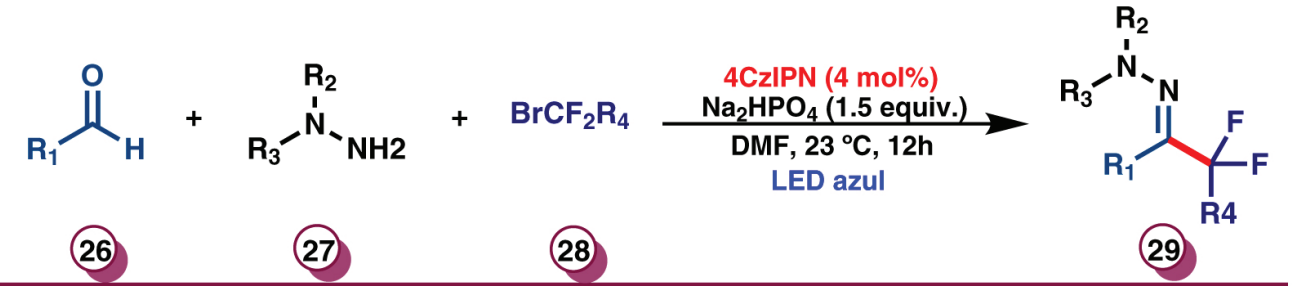

Exemplos Selecionados:<smiles>CCOC(=O)/C(=N\N(Cc1ccccc1)c1ccc(Cl)cc1)C(F)(F)C(=O)OCC</smiles>

29a: $70 \% E / Z=13: 1$<smiles>O=C(N=C(c1ccc(Cl)cc1)C(F)(F)F)C1(F)CCCC1</smiles>

29b: $93 \%$<smiles>FC(F)(/C(=N/N1CCOCC1)c1ccc(Cl)cc1)c1nc2ccccc2o1</smiles>

29c: $61 \%$

Esquema 11. Acoplamento multicomponente entre aldeídos, hidrazonas e espécies bromodifluoradas catalizado por 4CzIPN

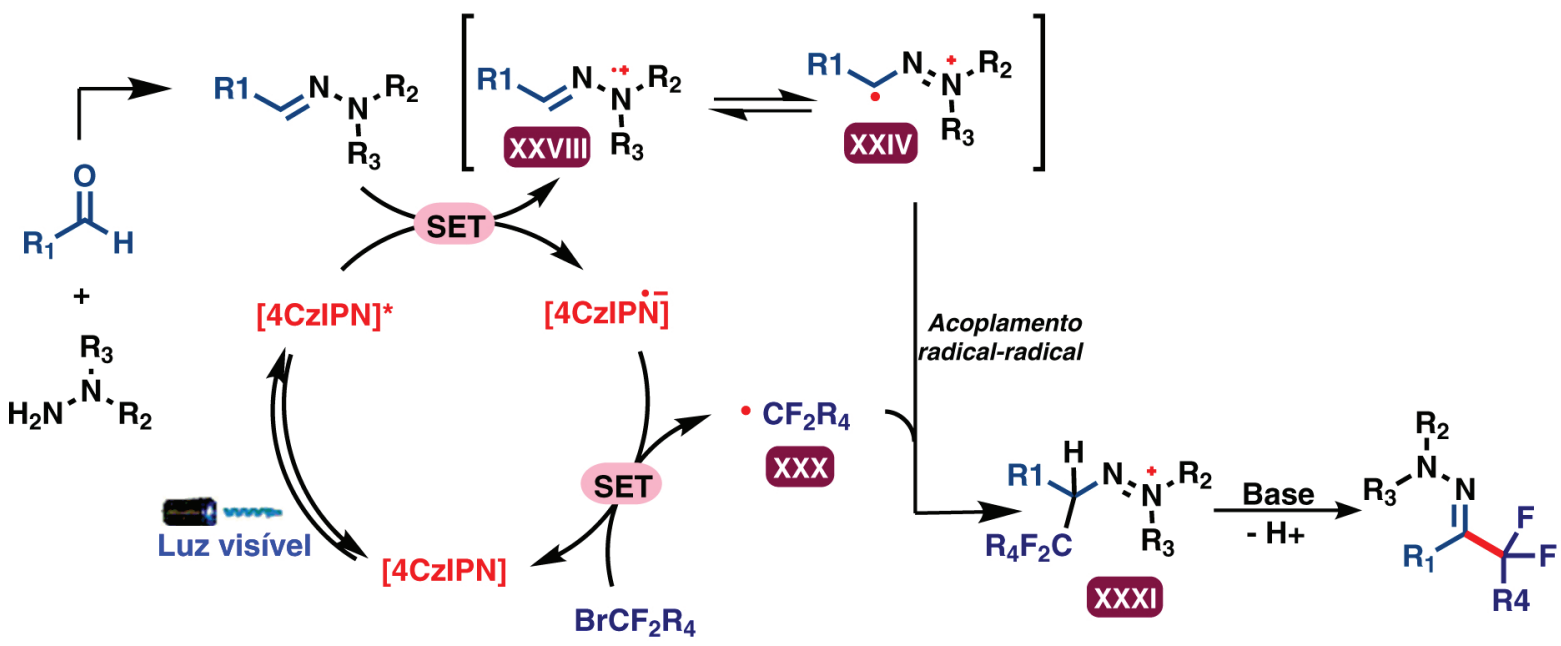

Figura 17. Proposta de mecanismo para a formação de moléculas contendo espécies difluormetilênicas

Diversos exemplos foram realizados a partir desse sistema reacional, tendo sido obtidos bons rendimentos (51-93\%) na conversão de aldeídos contendo substituintes doadores e retiradores de elétrons, independentemente da posição do substituinte no anel aromático.

Outro sistema catalítico fazendo uso de um metal de transição para uma catálise dupla foi reportado por Mariano, Wang e colaboradores, no qual um sistema catalítico duplo 4CzIPN/Ni sob irradiação de diodo emissor de luz azul foi usado como precursor radicalar na formilação de haletos acrílicos empregando o 2,2-dietoxiácido acético (Esquema 12). ${ }^{39}$

No mecanismo proposto pelos autores, a abstração de um elétron do ácido glioxílico pelo fotocatalisador no seu estado excitado leva à formação do radical XXXII acompanhada da liberação de $\mathrm{CO}_{2}$. O radical XXXII então se adiciona ao complexo de $\mathrm{Ni}(0)$ para a formação do complexo diacetal-Ni(I) XXXIII que, após a inserção oxidativa do composto 31, leva à formação do complexo de Ni(III) XXXIV. A reação prossegue pela eliminação redutiva do
$\mathbf{R}$<smiles>[X]c1ccccc1</smiles>

(30)<smiles>CCOC(OCC)C(=O)O</smiles>

(31)
4CZIPN (5 mol \%)

$\mathrm{NiCl}_{2} \cdot 6 \mathrm{H}_{2} \mathrm{O}(2 \mathrm{~mol} \%)$ dtbbpy (24 mol \%)

$\mathrm{Cs}_{2} \mathrm{CO}_{3}$ (1.5 equiv.)

DMF, 24-48 h, r.t

LED azul

$\mathrm{X}=$ OTf, Br, Cl

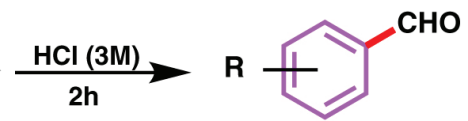

(32)

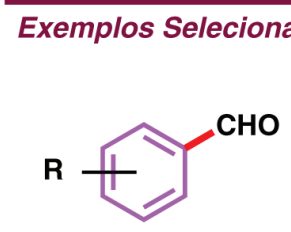

32a: $R=4-\mathrm{CN} ; 75 \%$

32b: $R=3-C N ; 60 \%$

32c: $R=2-C N ; 52 \%$

32d: $\mathbf{R}=4-\mathrm{CF}_{3} ; 52 \%$

32e: $\mathrm{R}=4-\mathrm{CO}_{2} \mathrm{Me} ; 85 \%$<smiles>N#CC(=O)c1ccc(C(=O)c2ccccc2)cc1</smiles><smiles>O=Cc1cccnc1</smiles>

Esquema 12. Formilação de haletos de arila catalisada por $4 C z I P N$ 
diacetal arílico, que é convertido ao aldeído arílico correspondente após tratamento com solução aquosa ácida (Figura 18).

O 4CzIPN mostrou-se fator determinante para a ocorrência dessa reação, visto que a troca desse organofotocalisador por Mes-Acr e por Eosina Y não levou à formação do aldeído. Foram realizados diversos exemplos com diferentes grupos funcionais, tendo sido obtidos rendimentos de 45 a $90 \%$.

Molander e colaboradores ainda investigaram a síntese de flavanonas através de uma catálise dupla fotoredox com níquel (Esquema 13). ${ }^{40}$ Flavanonas são metabólitos secundários dos flavanoides e são abundantes na natureza, estando presentes, por exemplo, em frutas cítricas. ${ }^{41}$ Seus usos mais comuns são em suplementos para dieta e como potentes agentes terapêuticos, no combate à ansiedade ${ }^{42}$ e como inibidor da transcriptase reversa da HIV-1. ${ }^{43}$ De maneira geral, as flavanonas são obtidas a partir de chalconas. Neste trabalho, no entanto, Molander propôs a obtenção dessa classe de compostos através de um acoplamento cruzado entre haletos de arila e heteroarila e derivados do 2-trifluorboratocromanona.

A escolha do NiCl2.DME como catalisador metálico se deu devido a sua estabilidade e facilidade de manuseio. Já a escolha do organofotocalisador levou em consideração, prioritariamente, o preço. $\mathrm{O}$ uso do catalisador de irídio, $\operatorname{Ir}\left[\mathrm{dFCF}_{3} \mathrm{ppy}\right]_{2}(\mathrm{bpy}) \mathrm{PF}_{6}$, resultou em um bom rendimento, porém, ele apresenta um alto custo, conforme mencionado anteriormente. Já o Eosina Y e o Mes-Acr, cujos custos são menores, não acarretaram a obtenção de produto. O 4CzIPN, por outro lado, além de apresentar baixo custo, apresentou desempenho superior ao do catalisador de irídio, sendo, portanto, o escolhido para dar continuidade ao trabalho.

Foram obtidos 13 compostos com rendimentos de 27 a $92 \%$, o que permitiu o estudo de como a natureza e a posição de diferentes substituintes afetam a reatividade dos compostos. Foi possível notar que, enquanto um anel de piridina deficiente de elétrons produz um bom resultado ( $82 \%$ de rendimento), um anel de piridina doador de elétrons resulta em um rendimento de $5 \%$, diminuindo muito a reatividade do precursor e, portanto, a eficiência da reação. O método proposto mostrou-se rápido, eficiente e sustentável na obtenção de flavanonas, assim como a catálise dupla demonstrou sua eficácia na obtenção de estruturas únicas, já que as reações ocorrem via mecanismo não usual para acoplamentos cruzados.

$\mathrm{O}$ acoplamento cruzado de haletos de alquila com ligações $\mathrm{C}\left(\mathrm{sp}^{3}\right)-\mathrm{H}$ mantém-se desafiador na síntese orgânica. Esse ano, nosso grupo de pesquisa, em colaboração com o professor König, reportou uma estratégia de acoplamento cruzado $\mathrm{C}\left(\mathrm{sp}^{3}\right)-\mathrm{C}\left(\mathrm{sp}^{3}\right)$ entre haletos de alquila e ésteres via catálise dupla fotoredox utilizando o 4CzIPN e níquel, além de carbonato de sódio como base (Esquema 14). ${ }^{44}$

De acordo com o mecanismo proposto (Figura 19), a adição oxidativa do haleto de alquila ao complexo de $\mathrm{Ni}(0)$ gera o complexo XXXV que, por sua vez, é oxidado pelo fotocatalisador no estado excitado, fornecendo o correspondente complexo XXXVI. Esse complexo XXXVI pode absorver luz visível e sofrer fotoeliminação,

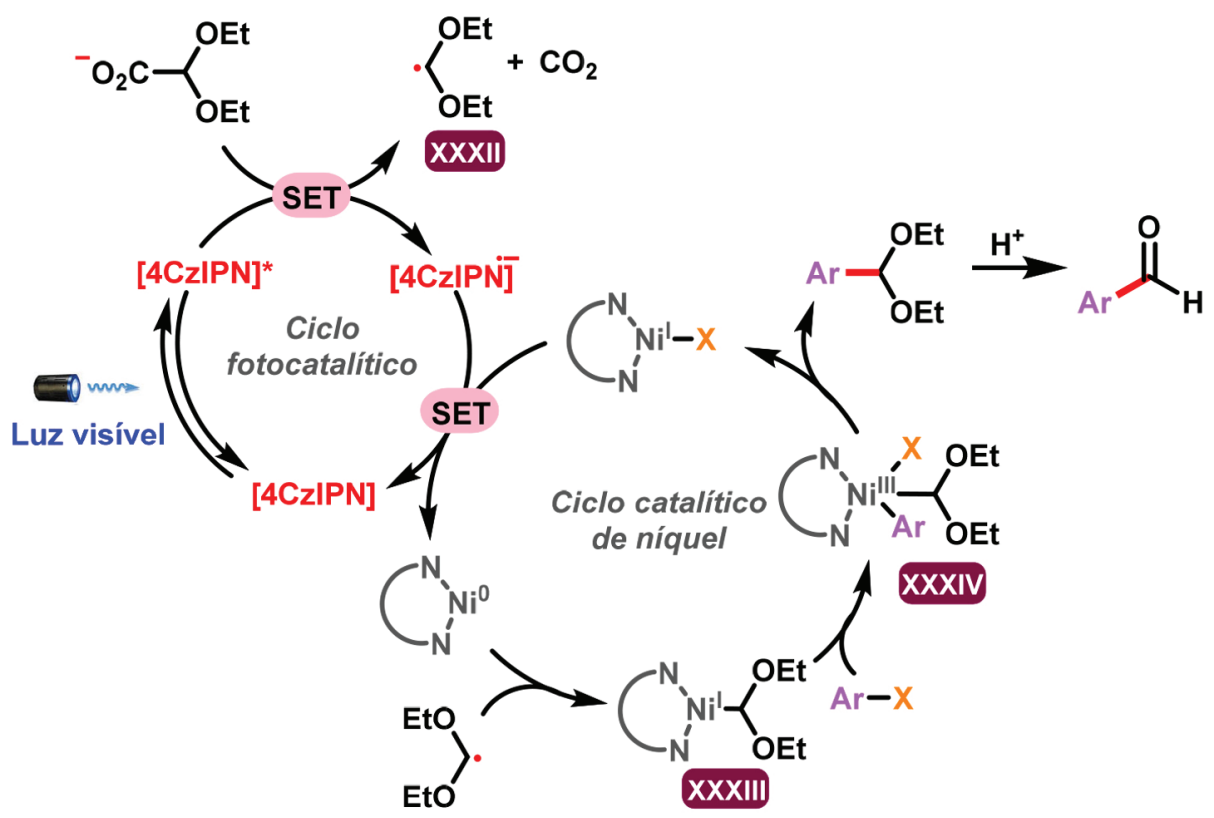

Figura 18. Proposta de mecanismo para a formação de aldeídos $\alpha$-arílicos a partir da fotocatálise dupla<smiles></smiles>

(33)
4CzIPN (2.5 mol \%) $\mathrm{NiCl}_{2}$.DME (5 mol \%) dtbbpy $(5 \mathrm{~mol} \%)$ $\mathrm{KH}_{2} \mathrm{PO}_{4}$ (2 eq.) Dioxano, 16-36h LED azul

(34)

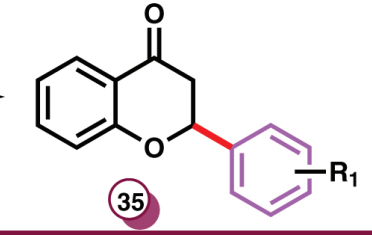

Exemplos Selecionados:<smiles>CC(C)C1CC(=O)c2ccccc2O1</smiles><smiles>Cc1cccc(C)c1</smiles>

35a: $78 \%$<smiles>Cc1ccc(C(F)(F)F)cc1</smiles>

35b: $73 \%$<smiles>[R6]c1ccccc1</smiles>

35c: $\mathbf{5 5 \%}$<smiles>[123I]c1ccc2occc2c1</smiles>

35d: $77 \%$<smiles></smiles>

35e: $92 \%$

Esquema 13. Obtenção de flavanonas através de catálise dupla 


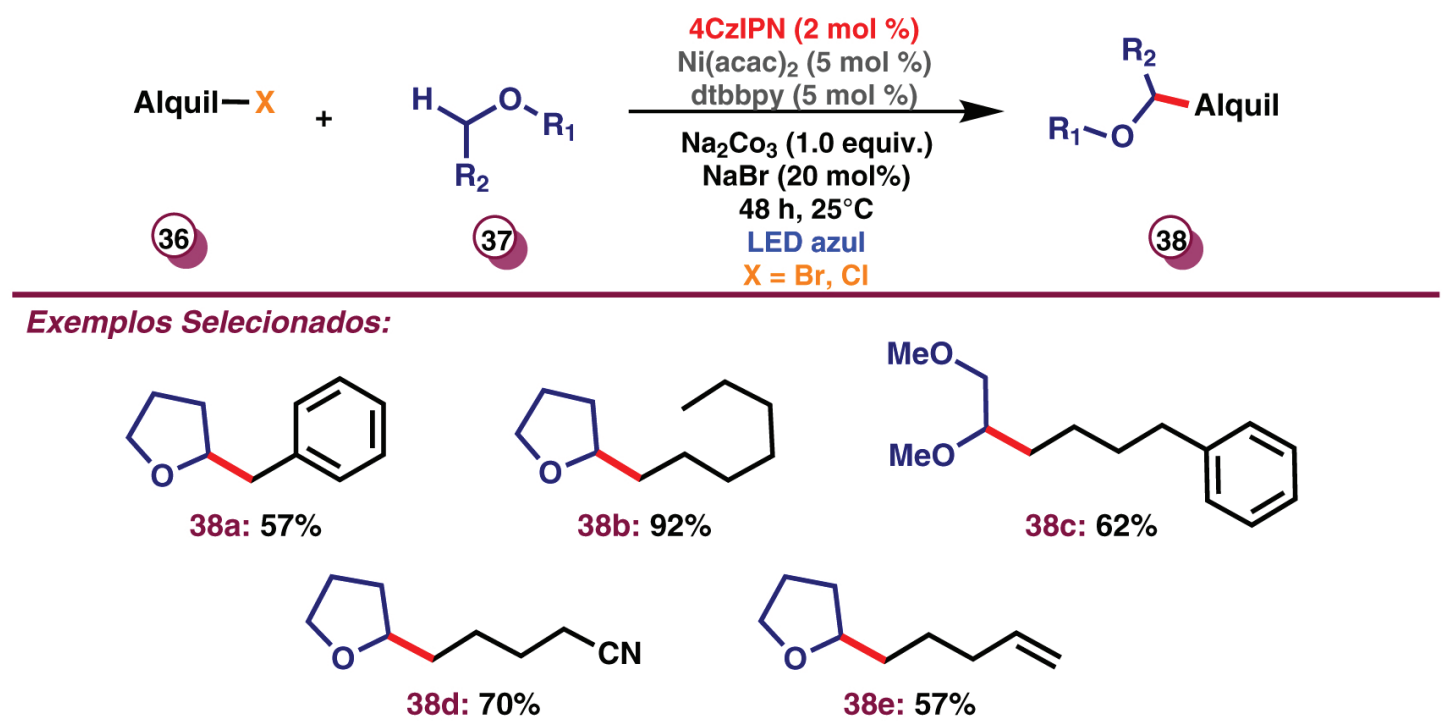

Esquema 14. Acoplamento cruzado $C\left(s p^{3}\right)$-C $\left(s p^{3}\right)$ de haletos de alquila com ésteres, via catálise dupla fotoredox

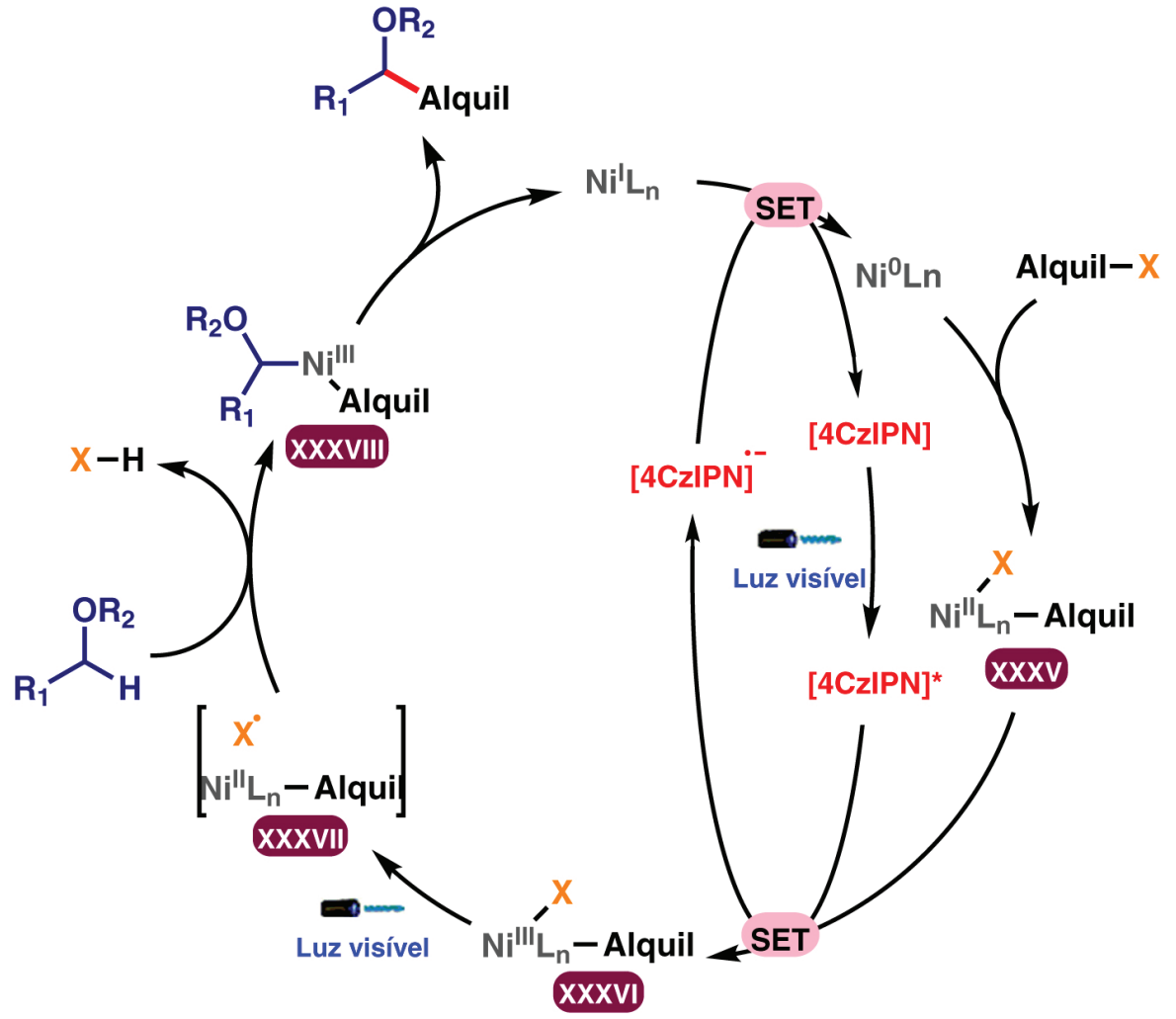

Figura 19. Proposta de mecanismo para o acoplamento cruzado $C\left(s p^{3}\right)-C\left(s p^{3}\right)$ via catálise dupla fotoredox

gerando o radical XXXVII eletrofílico. Em seguida, a espécie radicalar XXXVII atua como um agente de transferência de átomo de hidrogênio, abstraindo o átomo de hidrogênio do carbono $\alpha$ ao oxigênio, gerando, portanto, um radical centrado no carbono que se adiciona ao complexo de Ni(II) (XXXVII). Por fim, ocorre uma eliminação redutiva formando o produto de acoplamento cruzado e o complexo de $\mathrm{Ni}(\mathrm{I})$ que, posteriormente, é reduzido para $\mathrm{Ni}(0)$ pelo $4 \mathrm{CzIPN}{ }^{*}$, regenerando ambas as espécies catalíticas ativas e fechando os dois ciclos catalíticos.

Foi realizado um experimento controle com o intuito de averiguar se o 4CzIPN atuou como fotocatalisador de transferência de energia. Esse experimento consistiu em irradiar luz UV no meio reacional na ausência do fotocatalisador, processo que resultou na não formação de produto, o que sugere que a transferência de energia não desempenha um papel fundamental no mecanismo da reação proposta.

Foram obtidos 19 compostos com rendimentos na faixa de 11 a $92 \%$. Essa metodologia mostrou-se aplicável para acoplamento cruzado $\mathrm{C}\left(\mathrm{sp}_{3}\right)-\mathrm{C}\left(\mathrm{sp}_{3}\right)$ com catálise $\mathrm{Ni} / 4 \mathrm{CzIPN}$, sendo desnecessário o uso de um catalisador HAT adicional como no estudo de MacMillan. ${ }^{45}$ Como o 4 CzIPN apresentou-se como um catalisador eficiente e economicamente viável, não foram testados outros organofotocatalisadores.

\section{CONSIDERAÇÕES FINAIS}

A partir desses trabalhos reportados empregando o $4 \mathrm{CzIPN}$ 
como fotocatalisador de reações orgânicas é possível afirmar que ele possui ampla aplicabilidade na conversão de uma grande variedade de substratos em moléculas complexas e de grande interesse na indústria química, farmacêutica e na academia. Seus potenciais de oxirredução e tempo de meia-vida no estado excitado, equiparáveis aos fotocatalisadores baseados em metais de transição, fazem com que o 4CzIPN possa ser amplamente aplicado na maioria das metodologias tradicionais que fazem uso desses complexos de metais raros, apresentando-se como uma excelente alternativa metal-free, de baixo custo e de fácil obtenção. Ainda, a possibilidade da realização de alterações nas porções carbazólicas nele presentes, com o objetivo de alterar suas propriedades fotoquímicas, permite a possibilidade de sua aplicação em diversos sistemas catalíticos complexos não explorados até o presente momento. Somados esses fatores, pode-se concluir que o 4CzIPN se apresenta como um dos organofotocatalisadores mais versáteis, baratos e eficientes reportados na atualidade.

\section{REFERÊNCIAS}

1. Boyington, A. J.; Seath, C. P.; Zearfoss, A. M.; Xu, Z.; Jui, N. T.; J. Am. Chem. Soc. 2019, 141, 4147; Milligan, J. A.; Phelan, J. P.; Polites, V. C.; Kelly, C. B.; Molander, G. A.; Org. Lett. 2018, 20, 6840; Schwarz, J.; König, B.; Green Chem. 2016, 18, 4743; Wiles, R. J.; Phelan, J. P.; Molander, G. A.; Chem. Commun. 2019, 55, 7599; Prier, C. K.; Rankic, D. A.; MacMillan, D. W.; Chem. Rev. 2013, 113, 5322.

2. Anslyn, E. V.; Dougherty, D. A.; Modern Physical Organic Chemistry. University Science: Sausalito, 2006, cap. 16.

3. Balzani, V.; Photochemistry and Photophysics, Wiley-VCH Verlag GmbH \& Co. KGaA: Weinheim, 2014, cap. 3.

4. Kaji, H.; Suzuki, H.; Fukushima T.; Shizu K.; Suzuki K.; Kubo S.; Komino T.; Oiwa H.; Suzuki F.; Wakamiya A.; Murata Y.; Adachi C.; Nat. Commun. 2015, 6, 2.

5. Romero, N. A.; Nicewicz, D. A.; Chem. Rev. 2016, 116, 10075.

6. König, B.; Chemical Photocatalysis, Walter de Gruyter GmbH \& Co. KG: Boston, 2013, cap. 3.

7. Teegardin, K.; Day, J. I.; Chan, J.; Weaver, J.; Org. Process Res. Dev. 2016, 20, 1156; Prier, C. K.; Rankic, D. A.; MacMillan, D. W. C.; Chem. Rev. 2013, 113, 5322.

8. Liu, Z.; Zhang, Y.; Cai, Z.; Sun, H.; Cheng, X.; Adv. Synth. Catal. 2015, 357, 589.

9. Li, J.; Wang, H.; Liu, L.; Sun, J.; RSC Adv. 2014, 4, 49974.

10. Liu, H.; Feng, W.; Kee, C. W.; Zhao, Y.; Leow, D., Pan, Y.; Tan, C. H.; Green Chem. 2010, 12, 953.

11. Pan, Y.; Kee, C. W.; Chen, L.; Tan, C. H.; Green Chem. 2011, 13, 2682.

12. Speckmeier, E.; Fischer, T. G.; Zeitler, K.; J. Am. Chem. Soc. 2018, 140, 15353.

13. Lambert, C. R.; Kochevar, I. E.; Photochem. Photobiol. 1997, 66, 15.

14. DiRocco, D.; Electrochemical Series of Photocatalysts and Common Organic Compounds, Merck, 2014.

15. Uoyama, H.; Goushi, K.; Shizu, K.; Nomura, H.; Adachi, C.; Nature 2012, 492, 234.

16. Yokoyama, M.; Inada, K.; Tsuchiya, Y.; Nakanotani, H.; Adachi, C.; Chem Comm. 2018, 54, 8261.

17. Jiao, L.; Pang, W.; Zhou, J.; Wei, Y.; Mu, X.; Bai, G.; Hao, E.; J. Org. Chem. 2011, 76, 9988.

18. Speckmeier, E.; Fischer, T. G.; Zeitler, K.; J. Am. Chem. Soc. 2018, 140, 15353.
19. Engle, S. M.; Kirkner, T. R.; Kelly, C. B.; Org. Synth. 2019, 96, 455.

20. https://www.ossila.com/products/4czipn?variant $=8778942578805$, acessada em outubro 2020.

21. Kelly, C. B.; Patel, N. R.; Primer, D. N.; Jouffroy, M.; Tellis, J. C.; Molander, G. A.; Nat. Protoc. 2017, 12, 472.

22. Shang, T.; Lu, L.; Cao, Z.; Liu, Y.; He, W.; Yu, B.; Chem. Commun. 2019, 55, 5408

23. Buzzetti, L.; Crisenza, G. E. M.; Melchiorre, P.; Angew. Chem., Int. Ed. 2019, 58,3730 .

24. Griller, D.; Ingold, K. U.; Acc. Chem. Res. 1980, 13, 317; Bowry, V. W.; Lusztyk, J.; Ingold, K. U.; J. Am. Chem. Soc. 1991, 113, 5687.

25. Roessler, M. M.; Salvadori, E.; Chem. Soc. Rev. 2018, 47, 2534.

26. Simmons, H. E.; Smith, R. D.; J. Am. Chem. Soc. 1958, 80, 5323.

27. Phelan, J. P.; Lang, S. B.; Compton, J. S.; Kelly, C. B.; Dykstra, R.; Gutierrez O.; Molander, G. A.; J. Am. Chem. Soc. 2018, 140, 8037.

28. Milligan, J. A.; Phelan, J. P.; Polites, V. C.; Kelly, C. B.; Molander, G. A.; Org. Lett. 2018, 20, 6840.

29. Milligan, J. A.; Burns, K. L.; Le, A. V.; Polites, V. C.; Wang, Z-J.; Molander, G. A.; Kelly, C. B.; Adv. Synth. Cat. 2020, 362, 242.

30. Cai, S.; Tian, Y.; Zhang, J.; Liu, Z.; Lu, M.; Weng, W.; Huang, M.; Adv. Synth. Catal. 2018, 360, 4084.

31. Huang, H.-L.; Yan, H.; Gao, G.-L.; Yang, C.; Asian J. Org. Chem. 2015 , 4,674 .

32. Lu, M.; Liu, Z.; Zhang, J.; Tian, Y.; Qin, H.; Huang, M.; Hu, S.; Cai, S.; Org. Biomol. Chem. 2018, 16, 6564.

33. Raj, M.; Mahesh, S.; Tang K.; Molecules 2018, 23, 2615.

34. Alandini N.; Buzzetti L.; Favi, G.; Schulte, T.; Candish, L.; Collins, K.D.; Melchiorre, P.; Angew. Chem., Int. Ed. 2020, 59, 2.

35. Lu, M.; Qin, H.; Lin, Z.; Huang, M.; Weng, W.; Cai, S.; Org. Lett. 2018, 20, 7611 .

36. Patel, N. R.; Kelly, C. B.; Siegenfeld, A. P.; Molander, G. A.; ACS Catal. 2017, 7, 1766.

37. Li, J.-X.; Li, L.; Zhou, M.-D.; Wang, H.; Org. Chem. Front. 2018, 5, 1003.

38. Kirsch, P.; Modern Fluoroorganic Chemistry: Synthesis, Reactivity, Applications, Wiley-VCH: Weinheim, 2004, cap. 4.

39. Huang, H.; Li, X.; Yu, C.; Zhang, Y.; Mariano, P. S.; Wang, W.; Angew. Chem., Int. Ed. 2017, 56, 1500.

40. Matsui, J. K.; Molander, G. A.; Org. Lett. 2017, 19, 436.

41. Gattuso, G.; Barreca, D.; Gargiulli, C.; Leuzzi, U.; Caristi, C.; Molecules 2007, 12, 1641.

42. Viola, H.; Wasowski, C.; Destein, M. L.; Wolfman, C.; Silveira, R.; Dajas, F.; Medina, J. H.; Paladini, A. C.; Planta Med. 1995, 61, 213; Wolfman, C.; Viola, H.; Paladini, A.; Dajas, F.; Medina, J. H.; Pharmacol. Biochem. Behav. 1994, 47, 1; Wolfman, C.; Viola, H.; Wasowski, C.; Destein, M. L.; Silveira, R.; Dajas, F.; Medina, J. H.; Paladini, A. C.; J. Neurochem. 1995, 65, 167.

43. Xu, Z.-Q.; Buckheit, R. W.; Stup, T. L.; Flavin, M. T.; Khilevich, A.; Rizzo, J. D.; Lin, L.; Zembower, D. E.; Bioorg. Med. Chem. Lett. 1998, $8,2179$.

44. Santos, M. S.; Corrêa, A. G.; Paixão, M. W.; König, B.; Adv. Synth. Catal. 2020, 362, 2367.

45. Le, C.; Liang, Y.; Evans, R. W.; Li, X.; MacMillan, D. W. C.; Nature 2017, 547, 79 . 